\title{
Decisions from Valuations of Unknown Payoff Distributions
}

\author{
Ido Erev, \\ Faculty of Industrial Engineering \& Management, Technion, erevido@gmail.com \\ Yefim Roth, \\ Department of Human Services, University of Haifa, rothefim@gmail.com \\ Doron Sonsino, \\ Department of Economics, Ben-Gurion University of the Negev, and Cyprus International Institute \\ of Management (CIIM) (as of January 1, 2022), sonsino.doron@gmail.com
}

\begin{abstract}
Four experiments are presented that clarify the impact of experience on the way people use valuations. In each of the 100 trials of Study 1, participants were asked to choose between the status quo and an unknown binary lottery based on valuations by two expert systems: a well-calibrated "expert" reporting the expected values, and an expert that ignores the low probability outcome and reports the medians (that equaled the modes). The results suggest that experience decreased the inclination to follow the recommendation of the well-calibrated expert. This deviation from maximization appears to reflect two biases: the tendency to follow the expert that has recommended the action that provided higher payoff in most cases, and the tendency to follow the more extreme valuation. Studies 2 and 3 suggest similar reliance on experts that recommend the best choice in most trials, in choices between two payoff distributions, and even when these experts do not provide the median or the mode of the distributions. Study 4 shows that the impact of experts that direct people toward the optimal choice can be increased by exaggeration (inflating the estimated advantage of the payoff maximizing option). However, the long-term impact of exaggeration depends on the proportion of cases in which the optimal choice leads to the best payoff; a lasting positive effect of exaggeration was observed only when this proportion was high. These results can be captured by assuming several "expert weighting rules" and the selection between the rules based on small samples of past experiences.
\end{abstract}

Keywords: decisions from experience, black swan, underweighting of rare events, advice taking 


\section{Introduction}

New big data technologies have increased the frequency — and the importance — of decisions based on predictions of the expected outcomes of the feasible alternatives. For instance, while selecting the best possible route, drivers can now rely on estimated driving times provided by "expert systems" such as Google Maps and Waze. Similarly, when choosing what to wear before leaving home, people can rely on different estimates of the weather variables. The decision makers in such scenarios can utilize expert systems and learn how to use them optimally based on feedback obtained from repeated experiences.

While most previous studies on the use of experts' predictions and advice focus on decisions that are made before the decision makers gain experience with using the experts' advices (e.g., Benjamin \& Budescu, 2015; Bonaccio \& Dalal, 2006; Budescu et al., 2012; Cabantous et al., 2011; Erev \& Cohen, 1990), recent research (Bolton \& Katok, 2018; Radzevick \& Moore, 2011) demonstrates the importance of studying the impact of this experience. ${ }^{1}$ In one of the conditions examined by Bolton and Katok (2018), the participants were asked to repeatedly choose between "taking the cost of 25 tokens" and "taking the risk of losing 100 tokens with probability p." The value of $\mathrm{p}$ varied between trials, and participants in two of the experimental groups received one of two advices: accurate estimation of the value of p (e.g., "the loss probability in this trial is 0.20 ") or direct recommendation ("Take the risk" when the risk maximized the expected value [EV] and "Take the cost" when the cost maximized EV). The results reveal that in the very first trial (before receiving feedback), the EV maximization rate was higher in response to the direct recommendation than to the accurate estimation alone. However, the availability of feedback reversed this pattern; the choice rates after the first trial suggest a tendency to trust and use the accurate estimations more than the direct recommendations.

Bolton and Katok's analysis focuses on a simple situation in which decision makers know the possible outcomes and the shape of the payoff distributions. The current research extends their analysis by considering situations in which advice, like the output of the expert systems described above, is given as point estimates (or "valuations") of the realizations of unknown distributions.

Our analysis starts by examining the use of valuations in the experimental paradigm presented in

\footnotetext{
${ }^{1}$ Benjamin \& Budescu, (2015) examined situations in which advisers learn the distribution from experience and decision makers gain experience with different types of advisers. However, their paper does not examine the impact of feedback concerning the outcomes from decisions made based on the advice. Radzevick \& Moore, (2011) found an initial tendency to prefer overconfident advisors and an increase in sensitivity to accuracy with experience.
} 
Figure 1. In each trial, the decision makers (participants) are asked to choose between two prospects based on the valuation of each prospect provided by the two "experts." The participants do not receive prior information concerning the valuation rule, but receive immediate feedback after each trial.

Figure 1. The Main Screens in a Study that Uses the Basic "Decisions from Valuations" Paradigm Instructions: In each trial of this study, you will receive recommendations from two experts and will be asked to choose between two options. Your goal is to maximize your earnings.

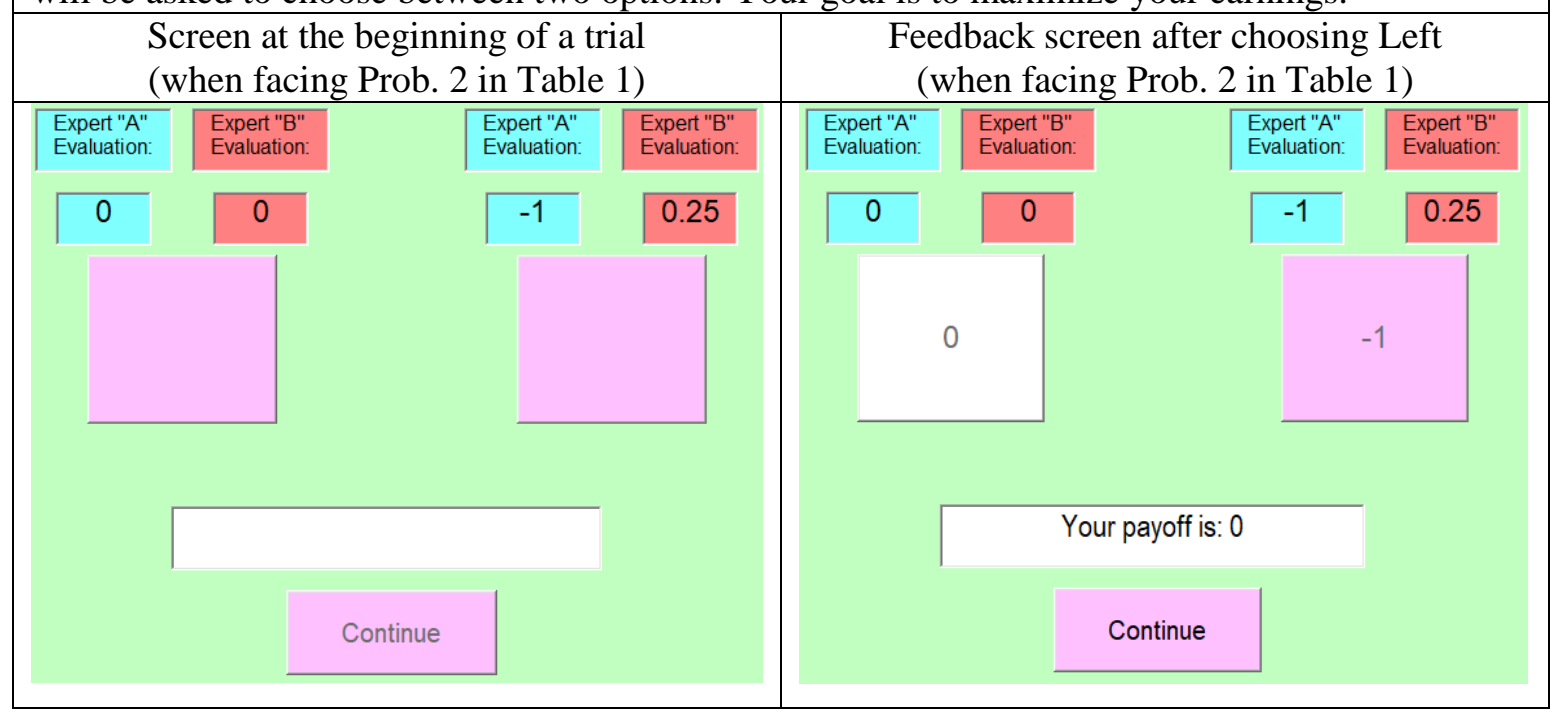

The "decisions from valuations" paradigm, can be described as a generalization of the clicking paradigm used in basic studies of decisions from experience (see Erev \& Haruvy, 2016). In the basic clicking paradigm, decision makers do not receive any information concerning the payoff distributions and must rely on their experience. Thus, the class of decisions from valuations we study falls between the situations examined in previous studies of advice taking, and the situations examined in previous studies of decisions from experience. This observation is potentially interesting as the natural generalizations from these two lines of research to the current setting can lead to contradicting predictions. One natural generalization of Bolton and Katok's study of the impact of experience on advice taking suggests that people are likely to learn to trust the better calibrated expert. ${ }^{2}$ When the best calibrated expert system is perfectly calibrated, and its valuations are identical to the expected values, this behavior is also predicted under the assumption that the decision makers will learn to maximize expected return. In contrast, the natural

\footnotetext{
${ }^{2}$ Experts are said to be well-calibrated when their estimates are identical to the expected value of the variables they estimate.
} 
generalization from previous studies of decision from experience suggests that the decision makers are likely to rely on small samples of past experiences. Reliance on small samples implies insufficient sensitivity to low probability extreme outcomes, and can lead to a preference for experts that ignore the extreme outcomes over well-calibrated experts. The current paper was designed to compare these contradicting predictions, and explore the difference between the impact of experience in basic repeated choice tasks and the current, more complex "decisions from valuations" setting.

The following section clarifies the evidence for, and the implications of, the reliance on small samples hypothesis. It focuses on a choice between a binary lottery and the status quo, given two expert valuations of the lotteries. "Expert EV" provides the expected value of the lottery, while "Expert Median" ignores the low probability outcome and reports the median (in the case of binary gambles, the median equals the mode). The analysis shows that reliance on small samples leads to a tendency to select the lottery when Expert Median recommends it (provides a positive valuation), even when the well-calibrated Expert EV recommends the status quo choice (and Expert Median's recommendation impairs the expected return).

Next, we present four experiments that explore human decisions from valuations. Study 1 documents the pattern predicted by the reliance on small samples hypothesis: a tendency to trust (i.e., behave according to the recommendations of) the expert providing valuation that equals the median and the mode, over the expert providing the EV of the lottery. In addition, the results reveal that more than a third of the participants behave as if they are averaging the two experts' valuations. Study 2 explores the generality of these patterns in more complex choice tasks and in cases where the experts tend to agree (provide similar recommendations). The results highlight the robustness of the main results of Study 1: a tendency to follow the expert that provides the median and a tendency to average the two experts' valuations. In addition, Study 2 demonstrates that in $27 \%$ of the trials in which the two experts favor the same option, the decision makers do not select the recommended option. Study 3 highlights the advantage of the reliance on small samples hypothesis over alternative explanations of the results of Studies 1 and 2.

Finally, Study 4 explores the value of two methods to increase the quality (i.e., EV maximization rate) of decisions in the current setting. It takes the point of view of a policy maker who tries to reduce the impact of experts that neglect rare events (and report the median). The first method builds on the reliance on small samples hypothesis. It improves the feedback provided to 
the decision makers by increasing the number of realizations from the valuated distributions. This method increased the maximization rate from $22 \%$ to $55 \%$. The second method decreases the quality of the information available to the decision makers by replacing Expert EV with a biased expert that provides more extreme valuations, ensuring that the average of the two experts will favor the maximizing options. This method rests on the hypothesis that many decision makers average the two experts, and the choices of these decision makers are determined by the more extreme expert. The results reveal that this method increased the initial maximization rate (to 58\%), but its effectiveness decreased with time (from $58 \%$ in the first block to $28 \%$ in the last block). In addition, Study 4 demonstrates that the joint impact of the two methods is synergistic: increasing feedback quality enhanced the positive impact of exaggeration, and increased the maximization rate to $89 \%$.

Our analysis is concluded with the presentation of a model that summarizes the main results of all four studies. The model assumes that the decision makers consider several "reactions to experts" rules (including a rule that implies the averaging of the two experts) and select between the rules based on small samples of past experiences.

\section{The Reliance on Small Samples Hypothesis, the EV and the Median}

Our interest in the implications of the reliance on small samples hypothesis stems from the results of four choice prediction competitions (Erev et al., 2010a, 2010b, 2017, Plonsky et al., 2019). While these competitions considered decisions from experience under different settings (individual decisions with limited feedback, market entry games with full feedback, and decisions under risk and ambiguity), the best models in all cases build on the reliance on small samples hypothesis. The descriptive value of this hypothesis can be the product of cognitive limitations, but can also reflect a sophisticated effort to approximate the optimal strategy under the reasonable belief that the world is dynamic (Plonsky et al., 2015).

In order to clarify the implications of the reliance on small samples hypothesis in the current setting, consider decisions between the status quo and mixed binary lotteries based on two valuations of these prospects: their EV and their median. Notice that the well-calibrated EV valuations has two attractive properties: using it maximizes expected return, and it minimizes the mean squared deviation (MSD, a proper scoring rule [Brier, 1950; Winkler, 1969]) between prediction and realization. Yet, in the current context, reliance on small samples can lead decision 
makers to prefer the expert ignoring the low probability outcome and reporting the median over the expert reporting the $\mathrm{EV}$.

To illustrate, consider an experiment in which the decision makers are faced with the 100 problems listed in Supplemental Materials (SM, henceforth) 1 (the left-hand side of Table 1 presents four representative problems). The experiment uses the valuation paradigm presented in Figure 1, and each trial focuses on a different problem. Recall that in this paradigm, the decision makers cannot see the payoff distributions, but can see the valuations of each option provided by two "experts." In the current example, one expert always provides the EV of the prospects, and the second expert always provides the median.

Table 1. Four of the 100 Problems Used to Clarify the Predictions of the Naïve Sampler Model, and Analyzed in Study 1

\begin{tabular}{|c|c|c|c|c|c|c|c|c|c|c|}
\hline \multirow{3}{*}{$\begin{array}{l}\text { Prob. } \\
\#\end{array}$} & & & & & & \multicolumn{5}{|c|}{$\begin{array}{l}\text { Choice rate of the risky prospect in a 100-trial experiment } \\
\text { with the problems listed in SM } 1\end{array}$} \\
\hline & \multicolumn{5}{|c|}{$\begin{array}{l}\text { Risky prospect (the lottery that provides } \mathrm{H} \text { with } \\
\text { Probability } \mathrm{pH} ; \mathrm{L} \text { otherwise) }\end{array}$} & \multicolumn{4}{|c|}{$\begin{array}{l}\text { Predictions of the naïve sampler model with } \\
\text { different sample size parameter }\end{array}$} & \multirow{2}{*}{$\begin{array}{c}\text { Human } \\
\text { subjects } \\
\text { (Study 1) }\end{array}$} \\
\hline & $\mathrm{H}$ & $\mathrm{pH}$ & $\mathrm{L}$ & EV & Median & $\kappa=1$ & $\kappa=5$ & $\kappa=10$ & $\kappa=15$ & \\
\hline 2 & 24.0 & 0.05 & -1.0 & 0.25 & -1.0 & 0.05 & 0.21 & 0.35 & 0.45 & 0.33 \\
\hline 52 & 1.0 & 0.95 & -24.0 & -0.25 & 1.0 & 0.95 & 0.79 & 0.65 & 0.55 & 0.70 \\
\hline 74 & 0.8 & 0.9 & -12.8 & -0.56 & 0.8 & 0.90 & 0.62 & 0.42 & 0.30 & 0.67 \\
\hline \multirow[t]{2}{*}{24} & 12.8 & 0.1 & -0.8 & 0.56 & -0.8 & 0.10 & 0.38 & 0.58 & 0.70 & 0.47 \\
\hline & & & & & & \multicolumn{5}{|c|}{ Means over all 100 problems } \\
\hline \multicolumn{6}{|c|}{ Choice rate of the risky prospect } & 0.50 & 0.50 & 0.50 & 0.50 & 0.50 \\
\hline \multicolumn{6}{|c|}{ Median rate (consistent with Expert Median) } & 0.88 & 0.59 & 0.48 & 0.44 & 0.72 \\
\hline \multicolumn{6}{|c|}{ Maximization rate (consistent with Expert EV) } & 0.12 & 0.41 & 0.52 & 0.56 & 0.28 \\
\hline
\end{tabular}

Notes. All problems involved a choice between the described lottery and the status quo (" 0 with certainty"). In addition to these four problems, we analyzed the other 96 problems presented in SM 1. The final rows present the mean results over all 100 problems.

The "naive sampler" columns in Table 1 present the predictions of distinct quantifications of the reliance on small samples hypothesis. All the quantifications use a basic generalization of the naïve sampler model (Erev \& Roth, 2014) to the current setting. This generalization assumes random choice in the first trial $(\mathrm{t}=1$, first problem faced by the decision maker), and samplingbased choices in all subsequent trials. Each sampling-based choice includes three steps: (1) random sampling with replacement of $\kappa$ previous trials, (2) computing the average obtained payoff from following each expert in these trials (following the experts implies selecting the higher valued option according to this expert), and (3) selecting the option recommended (valued higher in the current trial) by the expert with the higher average in the sample. The entries show the expected probability of selecting the lottery with different values of $\kappa$ (different sample sizes). The analysis, summarized in the last row of Table 1, reveals a strong tendency to follow Expert Median when $\kappa$ is 
very small (e.g., $88 \%$ with $\kappa=1$, which implies a maximization rate of $12 \%$ ) and a reversal of this rate with an increase in the value of $\kappa$.

However, there are also reasons to doubt the descriptive value of the reliance on small samples hypothesis in the current setting. As noted above, it is possible that Figure 1's decisions from valuations task is more similar to the situations examined by Bolton and Katok (2018) than to abstract studies of decisions from experience. In particular, it is possible that the availability of the experts' valuations will lead the decision makers to focus on the accuracy and the calibration-of the experts rather than on the outcome of the implied decisions. Under this "focus on calibration" hypothesis, the decision makers are predicted to follow the well-calibrated expert. The following experiments evaluate these predictions.

\section{Experimental studies}

The current section presents four experiments that explore human behavior in decisions from valuations.

\section{Study 1}

The first study explores human behavior in the environment described above. The problems involve a choice between the status quo ("0 for sure") and a risky binary lottery that leads to a gain or a loss. Importantly, over the 100 problems, the expected payoff from choosing the risky lottery is zero.

Participants. Thirty Technion students volunteered to participate in exchange for a monetary payoff, which included a show-up fee of 10 shekels (about \$2.80) and a chance to earn an additional 10-shekel bonus. (The small number of subjects was induced by Covid19; one of the conditions of Study 4 below replicates the current study). The participants were informed that each of their choices would be added to their accumulated earned points (in accordance with the obtained payoff) and that the more points they earned, the higher their chance of obtaining the bonus. The experiment lasted, on average, less than 10 minutes and the mean final payoff was about $\$ 3.60(\mathrm{SD}=1.5)$.

Procedure. Each participant faced all 100 problems presented in SM 1 (four of the problems are also presented in Table 1) in random order. The pre-choice information was limited to two experts' valuations of each option (see Figure 1). The participants could neither observe the payoff distributions, nor were they informed about the experts using the EV and median rules. The 
location of the two experts was determined randomly for each subject before trial 1 (i.e., Expert EV was on the left side, and was called A, for roughly half of the subjects). Similarly, the location of the safer (status quo) and riskier options was determined randomly for each subject before trial 1. Each choice was followed by feedback concerning the realization of the two options, as shown in Figure 1. Hence, the participants could learn about the accuracy of — and the benefit of using - the valuations of the two experts only from their own experience.

\section{Results}

The left-hand side of Figure 2 presents the choice rates of the expected value maximizing option (higher valuation according to Expert EV) in 10 blocks of 10 trials, while the right-hand side presents the predictions of the post-hoc model discussed below. Table 1 and SM 1 present the choice rates by problem. The mean EV-rate (the choice rate of the option with higher valuation according to Expert EV) is 0.28 ( $\mathrm{SD}=0.18$ ). Thus, the mean Median-rate (the choice rate of the option with higher valuations according to Expert Median) is 0.72 . This difference, predicted by the reliance on small samples hypothesis, is highly significant $(t(29)=22.55, p<0.001$, Cohen's $d=$ 1.26).

Figure 2. Study 1: Mean Choice Rates of the EV maximizing option (EV-rate) and the Model Predictions
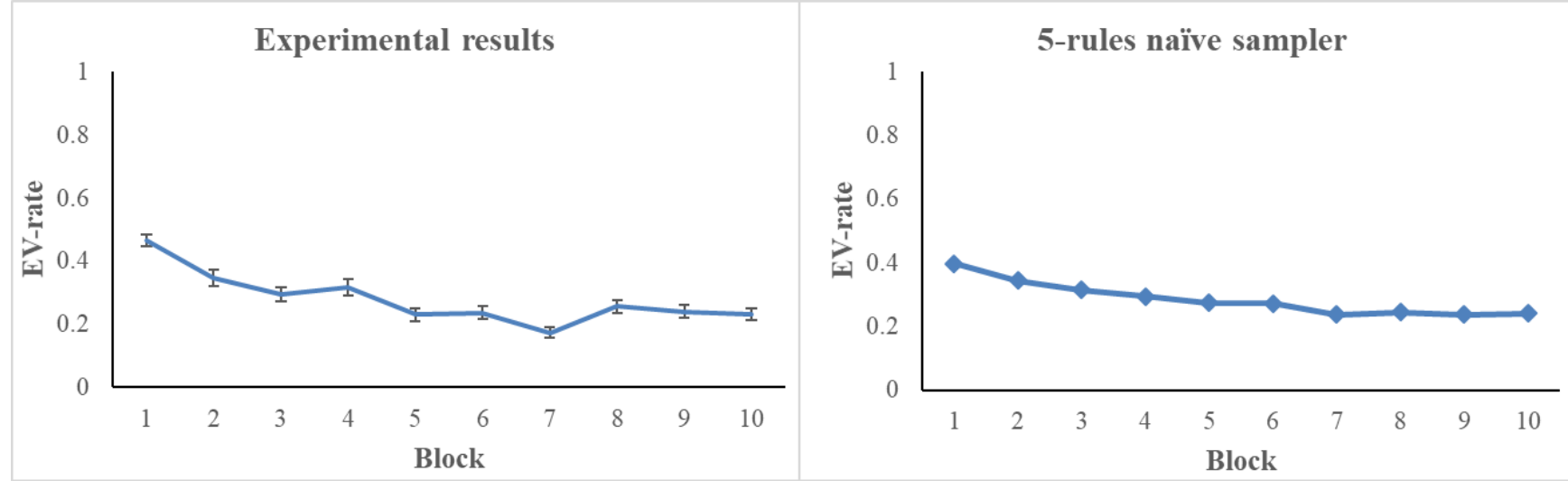

Notes. Mean choice rates of the EV maximizing option (that implies following Expert EV in 10 blocks of 10 trials (Left), and the predictions of the "5-rules naïve sampler" model described below (Right).

Figure 2 also shows that experience and full information regarding the obtained outcomes do not guard participants from impairing their expected payoff. While in the first block (first 10 trials), the mean maximization rate $(\mathrm{EV}$-rate) is $0.47(\mathrm{SD}=0.21)$, the maximization rate in the last 
10 trials (trials 91 to 100$)$ is significantly lower, $0.23(\mathrm{SD}=0.21, t(29)=4.37, p<0.001$, Cohen's d $=1.10)$.

In 96 of the 100 problems we studied, the difference between the medians (i.e., Expert Median's valuations) is larger than the difference between the EVs. In these cases, participants that select the option with the higher average valuation (over the two experts) behave as if they follow the Expert Median. To clarify the difference between the tendency to follow Expert Median or the average of the two experts, Table 2 presents the conditional risk rates (using the procedure suggested by Broomell, Budescu and Por, 2011). The results show a tendency to follow Expert Median even when the option suggested by this expert is not suggested by the average of the two experts. Yet, the results also suggest sensitivity to the average. We return to this observation below.

Table 2. The Conditional Risk Rates in Study 1

Expert Median

suggests

\begin{tabular}{cccc}
\hline & & Safe & Risk \\
\hline Average of the & Safe & 0.28 & 0.57 \\
two experts & & $(1440)$ & $(60)$ \\
\cline { 2 - 4 } suggests & Risk & 0.40 & 0.73 \\
& & $(60)$ & $(1440)$ \\
\hline
\end{tabular}

Note. Number of observations in parentheses.

Individual differences. Table 3 presents the choice rates consistent with five decision rules by participant. The five rules are: EV (select the option suggested by Expert EV), Median (select the option suggested by Expert Median), Average (select the option favored by the average of the two experts, Ariely et al., 2000; Larrick \& Soll, 2006; Winkler, 1981), Safe (select the option with the smaller difference between the two experts, the status quo in the current study), and Risk (select the option with the larger difference between the two experts, Harries et al., 2004). The decision to consider rule Average was made because it implies the rational choice under the assumption that both experts are equally useful, and to clarify the results summarized in Table 2. Rules Safe and Risk were considered as they are the rational choice assuming either that experts are ignored and the subject learns between the two sides (notice that the sides of the status quo did not change during the 100 trials), or if the subject has an extreme risk attitude. The results indicate large individual differences: two of the 30 participants were best fitted by the EV rule, 18 were best fitted by the Median rule, 11 by the Average, four by Safe, and six by Risk. The difference between the 
Median-rates and the EV-rates was significant for 22 of the 30 subjects (Sign test, $p<0.05$ ), and in 21 of the cases, the Median-rates were higher.

Table 3. Study 1: Choices Proportions Consistent with Five Distinct Rules by Subject

\begin{tabular}{|c|c|c|c|c|c|}
\hline $\begin{array}{c}\text { X } \\
\text { (rule name) } \\
\text { Participant }\end{array}$ & $\begin{array}{c}\text { Higher } \\
\text { expected value } \\
(E V)\end{array}$ & $\begin{array}{l}\text { Higher } \\
\text { median } \\
\text { (Median) }\end{array}$ & $\begin{array}{l}\text { Higher average } \\
\text { of the two } \\
\text { experts } \\
\text { (Average) }\end{array}$ & $\begin{array}{l}\text { Smaller difference } \\
\text { between the two } \\
\text { experts } \\
\text { (Safe) }\end{array}$ & $\begin{array}{c}\text { Larger difference } \\
\text { between the two } \\
\text { experts } \\
\text { (Risk) }\end{array}$ \\
\hline 1 & 0.23 & 0.77 & 0.75 & 0.69 & 0.31 \\
\hline 2 & 0.19 & 0.81 & 0.81 & 0.67 & 0.33 \\
\hline 3 & 0.49 & 0.51 & 0.51 & 0.01 & 0.99 \\
\hline 4 & 0.20 & 0.80 & 0.78 & 0.60 & 0.40 \\
\hline 5 & 0.50 & 0.50 & 0.50 & 1.00 & 0.00 \\
\hline 6 & 0.45 & 0.55 & 0.51 & 0.35 & 0.65 \\
\hline 7 & 0.57 & 0.43 & 0.43 & 0.79 & 0.21 \\
\hline 8 & 0.10 & 0.90 & 0.88 & 0.56 & 0.44 \\
\hline 9 & 0.23 & 0.77 & 0.79 & 0.41 & 0.59 \\
\hline 10 & 0.09 & 0.91 & 0.91 & 0.51 & 0.49 \\
\hline 11 & 0.20 & 0.80 & 0.80 & 0.46 & 0.54 \\
\hline 12 & 0.51 & 0.49 & 0.49 & 0.35 & 0.65 \\
\hline 13 & 0.10 & 0.90 & 0.88 & 0.46 & 0.54 \\
\hline 14 & 0.40 & 0.60 & 0.60 & 0.14 & 0.86 \\
\hline 15 & 0.14 & 0.86 & 0.82 & 0.44 & 0.56 \\
\hline 16 & 0.44 & 0.56 & 0.54 & 0.46 & 0.54 \\
\hline 17 & 0.36 & 0.64 & 0.64 & 0.64 & 0.36 \\
\hline 18 & 0.43 & 0.57 & 0.57 & 0.33 & 0.67 \\
\hline 19 & 0.37 & 0.63 & 0.63 & 0.37 & 0.63 \\
\hline 20 & 0.17 & 0.83 & 0.85 & 0.53 & 0.47 \\
\hline 21 & 0.24 & 0.76 & 0.74 & 0.48 & 0.52 \\
\hline 22 & 0.62 & 0.38 & 0.38 & 0.58 & 0.42 \\
\hline 23 & 0.07 & 0.93 & 0.89 & 0.55 & 0.45 \\
\hline 24 & 0.17 & 0.83 & 0.83 & 0.61 & 0.39 \\
\hline 25 & 0.54 & 0.46 & 0.48 & 0.54 & 0.46 \\
\hline 26 & 0.15 & 0.85 & 0.87 & 0.41 & 0.59 \\
\hline 27 & 0.18 & 0.82 & 0.82 & 0.60 & 0.40 \\
\hline 28 & 0.05 & 0.95 & 0.93 & 0.51 & 0.49 \\
\hline 29 & 0.06 & 0.94 & 0.92 & 0.56 & 0.44 \\
\hline 30 & 0.12 & 0.88 & 0.88 & 0.44 & 0.56 \\
\hline \# Best fitted & 2 & 18 & 11 & 4 & 6 \\
\hline Min & 0.05 & 0.38 & 0.38 & 0.01 & 0 \\
\hline Max & 0.62 & 0.95 & 0.93 & 1.00 & 0.99 \\
\hline Mean & 0.28 & 0.72 & 0.71 & 0.50 & 0.50 \\
\hline SD & 0.18 & 0.18 & 0.17 & 0.18 & 0.18 \\
\hline
\end{tabular}

Notes. All the rules are of the type "choose the option with property X." The top row presents the rule value of X (and the rule's name). The best fit is presented in bold; italic reflects fit not significantly different from the best (Sign test, $p<0.05$ ).

The choice rates of ten of the 30 participants were best fitted by Rules Safe or Risk. In five of these cases, Rules Safe or Risk fitted the choice rate significantly better than the other rules 
( $p<0.05$ in a sign test). This observation cannot be explained by the basic generalization of the naïve sampler model presented in Section 2 (which implies reliance on one of the two experts). We explore this observation below.

\section{Study 2}

Study 2 extends Study 1 by considering choices among more complex payoff distributions, and problems in which the two experts favor the same option. Specifically, it focuses on the 120 problems presented in SM 2, five of which are also presented in Table 4. These problems include all the choice problems studied in the 2015 choice prediction competition (CPC15, Erev et al., 2017), except for problems with ambiguity and degenerate problems in which the EV equals the median in both options. In order to evaluate the robustness of the results, Study 2 also used a modified payoff conversion (points to money) rule.

Participants. Forty Technion students volunteered to participate in exchange for a monetary payoff, which included a show-up fee of 20 shekels and the obtained payoff from one randomly selected trial. The conversion rate was 10 points $=1$ shekel. The experiment took roughly 10 minutes, and the mean final payoff was about $\$ 6$.

Procedure. The experimental design was identical to the one presented in Study 1, except that, each participant was faced with all 120 problems from SM 2 in random order.

\section{Results}

The left-hand side of Figure 3 presents the choice rates of the option with the higher valuation according to each expert in 12 blocks of 10 trials (the right-hand side of Figure 3 presents the predictions of the post-hoc model discussed below). ${ }^{3}$ The choice rates by problem are presented in SM 2 and Table 4. The mean EV-rate is 0.60 ( $\mathrm{SD}=0.10$ ), and the mean Median-rate is 0.70 (SD $=0.16)$. The difference is significant $(t(78)=-3.31, p<0.002$, Cohen's $\mathrm{d}=0.96)$. That is, the participants again behaved as if they paid more attention to Expert Median. Both rates are higher than 0.5 because the two experts favor the same option in 70 of the 120 problems. The mean choice rate of the options that were favored by both experts is 0.73 . Thus, in more than a quarter $(27 \%)$ of

\footnotetext{
${ }^{3}$ We ignore the $5 \%(4.16 \%)$ of trials where the mean (median) advisor provides the same evaluations for the two options.
} 
the trials, the decision makers behaved as if they did not trust the experts and selected the "valuations dominated" option (the option with lower valuation by both experts). Analyzing the cases in which the two experts favored different options reveals an EV-rate of $0.37(\mathrm{SD}=0.14)$. Thus, the Median-rate is 0.63 .

Table 4. Five of the Problems Analyzed in Study 2

\begin{tabular}{|c|c|c|c|c|c|c|c|c|c|c|c|c|c|}
\hline \multirow{3}{*}{$\begin{array}{c}\text { Prob. } \\
\text { \# }\end{array}$} & \multirow{2}{*}{\multicolumn{3}{|c|}{ Option 1}} & \multirow{2}{*}{\multicolumn{3}{|c|}{ Option 2}} & & & & & & \multicolumn{2}{|c|}{ Choice rates of Option 2} \\
\hline & & & & & & & \multicolumn{2}{|c|}{ Expected values } & \multicolumn{2}{|c|}{ Medians } & \multicolumn{2}{|c|}{ CPC15 } & \multirow{2}{*}{$\begin{array}{c}\text { Study } 2 \\
\text { From } \\
\text { valuations }\end{array}$} \\
\hline & H1 & $\mathrm{pH} 1$ & L1 & $\mathrm{H} 2$ & $\mathrm{pH} 2$ & L2 & EV1 & EV2 & Med1 & Med2 & $\begin{array}{l}\text { From } \\
\text { desc. }\end{array}$ & $\begin{array}{l}\text { From } \\
\text { exp. }\end{array}$ & \\
\hline 1 & 3 & 1.00 & . & 4 & 0.80 & 0 & 3.00 & 3.20 & 3 & 4.0 & 0.42 & 0.65 & 0.65 \\
\hline 2 & 3 & 0.25 & 0 & 4 & 0.20 & 0 & 0.75 & 0.80 & 0 & 0.0 & 0.61 & 0.62 & 0.43 \\
\hline 3 & -3 & 1.00 & . & 0 & 0.20 & -4 & -3.00 & -3.20 & -3 & -4.0 & 0.49 & 0.36 & 0.28 \\
\hline 8 & 2 & 1.00 & . & 101 & 0.01 & 1 & 2.00 & 2.00 & 2 & 1.0 & 0.55 & 0.42 & 0.28 \\
\hline \multirow[t]{4}{*}{5} & -1 & 1.00 & . & 0 & 0.95 & -20 & -1.00 & -1.00 & -1 & 0.0 & 0.48 & 0.64 & 0.70 \\
\hline & & & & & & & & & & & \multicolumn{3}{|c|}{$\begin{array}{c}\text { Means over all } 120 \\
\text { problems }\end{array}$} \\
\hline & & & & & & \multicolumn{5}{|c|}{ Choice rate of the option with higher median } & 0.59 & 0.66 & 0.70 \\
\hline & & & & & & \multicolumn{5}{|c|}{ Maximization rate } & 0.67 & 0.71 & 0.60 \\
\hline
\end{tabular}

Notes. Option $\mathrm{j}$ provides $\mathrm{Hj}$ with Probability $\mathrm{pHj}$; $\mathrm{Lj}$ otherwise. In addition to these five problems, Study 2 examined the other 115 problems presented in SM 2. The CPC15 columns present the choice rates of Option 2 observed by Erev et al. (2017, discussed here in Section "Relationship to description-experience gap"): "From desc." presents the rate in decisions from description (before getting feedback), and "From exp." presents the rate after receiving feedback. The right-hand column presents the current results. The last two rows present the mean results over all 120 problems.

Figure 3. Study 2: Mean Choice Rates and the Model Predictions
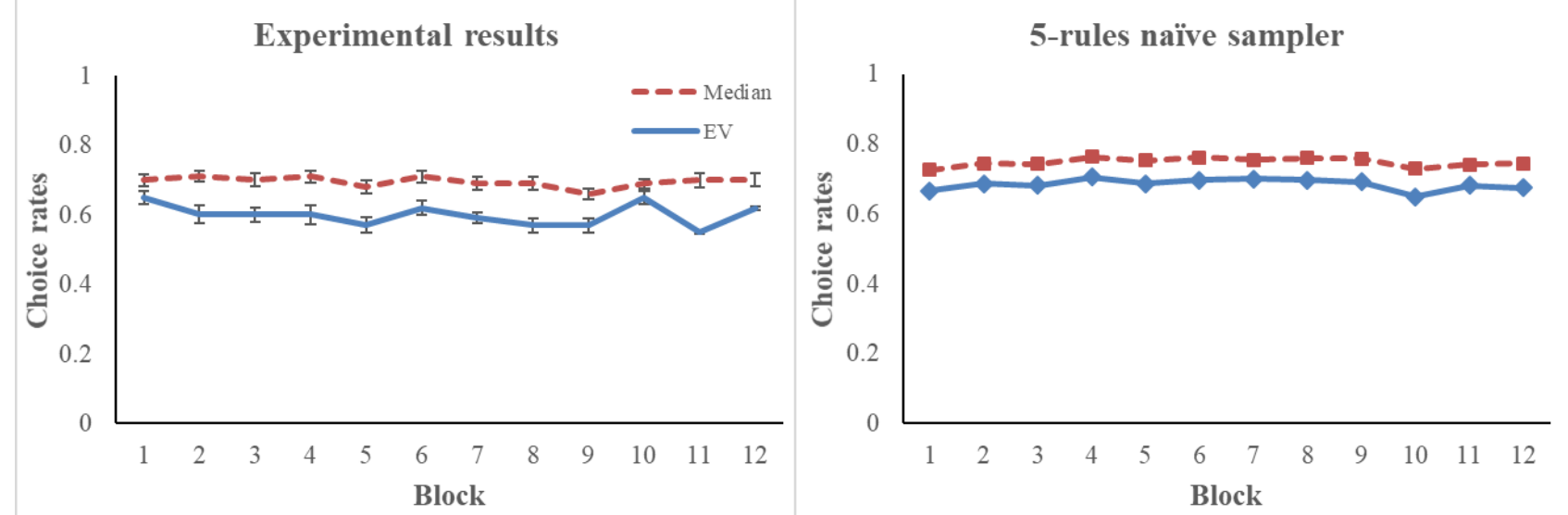

Notes. Mean choice rates of the option with the higher valuation according to each of the two experts (EV and Median) in 12 blocks of 10 trials (Left), and the predictions of the "5-rules naïve sampler" model described below (Right).

Table 5 presents the conditional risk rates. It shows that in the current study, the proportion of choices consistent with the average of the two experts is slightly larger than the proportion of choices consistent with Expert Median. 
Table 5. The Conditional Risk Rates in Study 2

\begin{tabular}{|c|c|c|c|c|c|c|c|c|c|}
\hline & \multicolumn{3}{|c|}{$\begin{array}{l}\text { Expert Median } \\
\text { Suggests }\end{array}$} & & & \multicolumn{3}{|c|}{$\begin{array}{l}\text { Expert Median } \\
\text { suggests }\end{array}$} \\
\hline & & Safe & Ind. & Risk & & & Safe & Ind. & Risk \\
\hline \multirow{3}{*}{$\begin{array}{l}\text { Average } \\
\text { of the } \\
\text { two } \\
\text { experts } \\
\text { suggests }\end{array}$} & Safe & $\begin{array}{c}0.28 \\
(2680) \\
\end{array}$ & $\begin{array}{l}0.42 \\
(40)\end{array}$ & $\begin{array}{l}0.44 \\
(80)\end{array}$ & \multirow{3}{*}{$\begin{array}{c}\text { Expert } \\
\text { EV } \\
\text { suggests }\end{array}$} & Safe & $\begin{array}{c}0.25 \\
(1680) \\
\end{array}$ & $\begin{array}{l}0.42 \\
(40)\end{array}$ & $\begin{array}{l}0.61 \\
(640)\end{array}$ \\
\hline & Ind. & --- & --- & --- & & Ind. & $\begin{array}{l}0.24 \\
(200)\end{array}$ & (0) & $\begin{array}{l}0.70 \\
(40)\end{array}$ \\
\hline & Risk & $\begin{array}{l}0.49 \\
(120)\end{array}$ & $\begin{array}{l}0.59 \\
(160)\end{array}$ & $\begin{array}{c}0.68 \\
(1720)\end{array}$ & & Risk & $\begin{array}{l}0.35 \\
(920)\end{array}$ & $\begin{array}{l}0.59 \\
(160)\end{array}$ & $\begin{array}{c}0.70 \\
(1120)\end{array}$ \\
\hline
\end{tabular}

Notes. Number of observations in parentheses. Ind. is indifference.

Individual differences. Table 6 presents the choice rates consistent with the five decision rules described above, using Table 3's format. The results show large individual differences, similar to the pattern documented in Study 1. In the current study, only one of the 40 participants was best fitted by the EV rule, 11 were best fitted by the Median rule, 12 by the Average, 10 by the minimum difference (Safe), and six by the maximum difference (Risk). The difference between the Median-rates and the EV-rates was significant for 14 of the 40 subjects (Sign test, $p<0.05$ ), and in all 14 cases, the Median-rates were higher. For four of the subjects, the difference between the Median- and the Average-rates was significant (Sign test, $p<0.05$ ), and the Average-rates were higher in all four cases.

Sixteen of the 40 participants (40\%) were more sensitive to the absolute difference between the expert's valuations (i.e., "Safe" or "Risk") than to the valuations themselves. Ten of them showed an inclination for rule "Safe" (smaller difference between the two valuations), while the other six choices were more consistent with rule "Risk" (larger difference between the two valuations). Sign test reveals that in 9 out of the 16 cases, one of the "Safe" or "Risk" rules fits the choice rate significantly better $(p<0.05)$ than any of the other three rules. These results, as well as the similar pattern documented in Study 1, suggest that at least some of the choices of the "valuations dominated" option are not merely random choices. The implications of these individual differences are further discussed in the "Implications to Descriptive Models," section below. 
Table 6. Study 2: Choices Proportions Consistent with Five Distinct Rules by Subject

\begin{tabular}{|c|c|c|c|c|c|}
\hline $\begin{array}{c}\text { X } \\
\text { (rule name) } \\
\text { Participant }\end{array}$ & $\begin{array}{l}\text { Higher } \\
\text { expected } \\
\text { value } \\
(\mathrm{EV})\end{array}$ & $\begin{array}{l}\text { Higher } \\
\text { median } \\
\text { (Median) }\end{array}$ & $\begin{array}{c}\text { Higher average } \\
\text { of the two } \\
\text { experts } \\
\text { (Average) }\end{array}$ & $\begin{array}{l}\text { Smaller difference } \\
\text { between the two } \\
\text { experts } \\
\text { (Safe) }\end{array}$ & $\begin{array}{l}\text { Larger difference } \\
\text { between the two } \\
\text { experts } \\
\text { (Risk) }\end{array}$ \\
\hline 1 & 0.68 & 0.73 & 0.72 & 0.61 & 0.39 \\
\hline 2 & 0.73 & 0.77 & 0.78 & 0.60 & 0.40 \\
\hline 3 & 0.56 & 0.52 & 0.53 & 0.28 & 0.72 \\
\hline 4 & 0.49 & 0.58 & 0.58 & 0.72 & 0.28 \\
\hline 5 & 0.66 & 0.76 & 0.77 & 0.69 & 0.31 \\
\hline 6 & 0.68 & 0.96 & 0.93 & 0.63 & 0.37 \\
\hline 7 & 0.55 & 0.66 & 0.63 & 0.67 & 0.33 \\
\hline 8 & 0.69 & 0.81 & 0.82 & 0.74 & 0.26 \\
\hline 9 & 0.56 & 0.79 & 0.74 & 0.56 & 0.44 \\
\hline 10 & 0.52 & 0.60 & 0.58 & 0.79 & 0.21 \\
\hline 11 & 0.53 & 0.56 & 0.55 & 0.41 & 0.59 \\
\hline 12 & 0.68 & 0.94 & 0.91 & 0.56 & 0.44 \\
\hline 13 & 0.63 & 0.57 & 0.61 & 0.46 & 0.54 \\
\hline 14 & 0.76 & 0.83 & 0.84 & 0.56 & 0.44 \\
\hline 15 & 0.52 & 0.47 & 0.50 & 0.34 & 0.66 \\
\hline 16 & 0.50 & 0.56 & 0.56 & 0.49 & 0.51 \\
\hline 17 & 0.61 & 0.72 & 0.70 & 0.74 & 0.26 \\
\hline 18 & 0.64 & 0.87 & 0.88 & 0.59 & 0.41 \\
\hline 19 & 0.51 & 0.57 & 0.54 & 0.74 & 0.26 \\
\hline 20 & 0.46 & 0.66 & 0.63 & 0.94 & 0.06 \\
\hline 21 & 0.72 & 0.90 & 0.95 & 0.56 & 0.44 \\
\hline 22 & 0.46 & 0.57 & 0.56 & 0.49 & 0.51 \\
\hline 23 & 0.61 & 0.72 & 0.72 & 0.69 & 0.31 \\
\hline 24 & 0.60 & 0.72 & 0.69 & 0.87 & 0.13 \\
\hline 25 & 0.47 & 0.69 & 0.65 & 0.63 & 0.37 \\
\hline 26 & 0.55 & 0.86 & 0.81 & 0.56 & 0.44 \\
\hline 27 & 0.69 & 0.90 & 0.89 & 0.53 & 0.47 \\
\hline 28 & 0.61 & 0.66 & 0.65 & 0.51 & 0.49 \\
\hline 29 & 0.77 & 0.88 & 0.92 & 0.56 & 0.44 \\
\hline 30 & 0.79 & 0.78 & 0.83 & 0.44 & 0.56 \\
\hline 31 & 0.45 & 0.42 & 0.42 & 0.32 & 0.68 \\
\hline 32 & 0.51 & 0.43 & 0.46 & 0.22 & 0.78 \\
\hline 33 & 0.50 & 0.55 & 0.55 & 0.62 & 0.38 \\
\hline 34 & 0.54 & 0.57 & 0.56 & 0.78 & 0.22 \\
\hline 35 & 0.64 & 0.83 & 0.81 & 0.56 & 0.44 \\
\hline 36 & 0.47 & 0.38 & 0.41 & 0.15 & 0.85 \\
\hline 37 & 0.74 & 0.89 & 0.92 & 0.58 & 0.42 \\
\hline 38 & 0.56 & 0.56 & 0.55 & 0.60 & 0.40 \\
\hline 39 & 0.60 & 0.64 & 0.66 & 0.37 & 0.63 \\
\hline 40 & 0.71 & 0.90 & 0.91 & 0.57 & 0.43 \\
\hline \# Best fitted & 1 & 11 & 12 & 10 & 6 \\
\hline Min & 0.45 & 0.38 & 0.41 & 0.15 & 0.06 \\
\hline Max & 0.79 & 0.96 & 0.95 & 0.94 & 0.85 \\
\hline Mean & 0.60 & 0.70 & 0.69 & 0.57 & 0.43 \\
\hline SD & 0.1 & 0.15 & 0.15 & 0.17 & 0.17 \\
\hline
\end{tabular}

Notes. Table 3's notations and format.

Relationship to description-experience gap. Using CPC15 (Erev et al., 2017) problems allows a comparison between decisions from (experts') valuations, examined here, and the 
decisions from description and experience examined in the CPC15 study. ${ }^{4}$ Table 4 focuses on five of the problems examined in the CPC15 study to clarify the description-experience gap. The "From Desc." column presents the choice rate of the riskier option in the first five trials in the CPC15 study. These first five decisions were made based on a complete description of the payoff distributions, prior to subjects receiving any feedback concerning the outcome of their previous choices. The "From Exp." column presents the choice rate of the riskier option in the last five trials of the CPC15 study. Feedback was provided after each choice starting in trial 6, and while making the last five decisions, the participants could rely on feedback from at least 15 past experiences with the particular problem.

The "From desc." column replicates three important phenomena studied by Kahneman and Tversky (1979): The Allais paradox (Allais 1953)/certainty effect (higher safe rate in Problem 1 than 2), the reflection effect (higher risk aversion in Problem 1 than 3), and overweighting of rare events (risk seeking in Problem 8 and risk aversion in 5). The "From exp." column indicates that experience reverses all three phenomena. Comparison of the "From valuations" column to the two CPC15 columns show that the gap between decisions from description and from valuations, is larger than the description-experience gap in all three cases.

Analysis of the choice rate of the options with the highest median (median-rate), over all 115 problems with distinct medians, revealed a similar pattern: The Median-rates were 0.59 from description, 0.66 from experience, and 0.70 from valuations. Sign test, using problem as a unit of analysis, reveals that all three differences are significant $(p<0.005)$.

\section{Study 3}

Study 3 explores three alternative explanations to the tendency to favor Expert Median in Studies 1 and 2. The most natural alternative explanation assumes that the results reflect the fact that in these studies, the median is almost always equal to the mode; thus, Expert Median provided exactly accurate valuation in most trials (see a related idea in Dietvorst \& Bharti, 2020). To evaluate if a tendency to favor the mode is a sufficient explanation to our result, Study 3 examines choice tasks in which the median differs from the mode. A second alternative explanation rests on the observation that in almost all problems in Studies 1 and 2, the differences between the medians

\footnotetext{
${ }^{4}$ Table 3's problems are five of the 30 problems examined in the "replication" experiment in CPC15. Each of 125 participants faced each of the 30 problems for 25 trials. The final payoff was determined by the sum of the show-up fee and one randomly selected choice.
} 
were larger than the differences between the EVs. Thus, participants that average the two experts are predicted to behave as if they follow expert Median. To test this explanation, Study 3 examines choice tasks in which the difference between the medians is smaller than the difference between the means. A third alternative explanation rests on the fact that the median minimizes the absolute difference between the valuation and the obtained outcomes. It is possible that the participants find this property attractive. Since this property of the median cannot be changed, Study 3 evaluates this explanation by comparing two conditions that differ with respect to the prediction of the reliance on small samples hypothesis. Condition Median-wins-more is similar to the conditions examined in Studies 1 and 2: following Expert Median lead to the best outcome in 83\% of the trials. In contrast, in Condition EV-wins-more, following Expert median leads to the best outcomes in only $10 \%$ of the trials (and following expert EV leads to the best outcome in the other 90\%).

Table 7 presents two of the 100 basic choice problems examined in Study 3. The realization of the error terms that was added to each prospect depended on the experimental condition and determined the proportion of trials in which Expert Median "wins” (leads to higher payoff) using the method developed by Cohen, Plonsky and Erev (2020). The term $\mathrm{u}_{10}$ was drawn from $\mathrm{u}[-5,+5]$, and the term $\mathrm{u}_{90}$ was set to equal $\mathrm{u}_{10}+1$ if $\mathrm{u}_{10}<4$, and $\mathrm{u}_{10}-9$ otherwise. Thus, the distribution of the two terms is identical $(\mathrm{u}[-5,+5])$, and the difference between these terms does not affect the EV or the median of the prospects. Yet, $\mathrm{u}_{90}$ was higher than $\mathrm{u}_{10}$ in $90 \%$ of the trials, and when the basic payoffs were similar, the ranking of the error terms determined the ranking of the final outcomes. The 100 basic problems (SM 3) were designed to ensure the same average EV for the Safe and Risk prospects. 
Table 7. Two of the Problems Analyzed in Study 3

\begin{tabular}{|c|c|c|c|c|c|c|c|}
\hline \multirow[t]{2}{*}{ Safe } & \multirow[t]{2}{*}{ Risk } & \multicolumn{2}{|c|}{ EV } & \multicolumn{2}{|c|}{ Median } & \multicolumn{2}{|c|}{$\begin{array}{l}\text { Choice rate of the } \\
\text { risky prospect }\end{array}$} \\
\hline & & Safe & Risk & Safe & Risk & $\begin{array}{c}\text { Median- } \\
\text { wins-more } \\
\varepsilon_{\mathrm{M}}=\mathrm{u}_{90}, \\
\varepsilon_{\mathrm{E}}=\mathrm{u}_{10} .\end{array}$ & $\begin{array}{c}\text { EV-wins- } \\
\text { more } \\
\varepsilon_{\mathrm{M}}=\mathrm{u}_{10} \\
\varepsilon_{\mathrm{E}}=\mathrm{u}_{90} .\end{array}$ \\
\hline $4+\varepsilon_{M}$ & $(4, .9 ;-7, .08 ;+103, .02)+\varepsilon_{\mathrm{E}}$ & 4 & 5.10 & 4 & 3.67 & 0.44 & 0.50 \\
\hline \multirow[t]{3}{*}{$4+\varepsilon_{\mathrm{E}}$} & $(4, .9 ;+13, .08 ;-97, .02)+\varepsilon_{M}$ & 4 & 2.70 & 4 & 4.33 & 0.53 & 0.37 \\
\hline & & & & & & \multicolumn{2}{|c|}{$\begin{array}{l}\text { Main results over all } \\
\text { problems }\end{array}$} \\
\hline & Choice rate of & he opti & ns with & higher & nedian: & 0.55 & 0.40 \\
\hline
\end{tabular}

Notes. $\varepsilon_{\mathrm{M}}, \varepsilon_{\mathrm{E}}$ denote the error terms associated with the options with the higher median and EV, respectively. $\mathrm{u}_{10}$ was drawn from $\mathrm{u}[-5,+5]$, and $\mathrm{u}_{90}=\mathrm{u}_{10}+1$ if $\mathrm{u}_{10}<4$, and $\mathrm{u}_{10}-9$ otherwise. Values in Bold highlight the highest valuations. In addition to these two problems, Study 3 examined the other 98 problems described in SM 3.

Participant. Eighty Technion students took part in this experiment in exchange for a financial payoff, similarly to Study 2 (the experiment took about 8 minutes and the mean payoff was again about $6 \$$ ).

Design and Procedure. The study used a between-subject design. Forty participants were assigned to Condition Median-wins-more and faced each of the 100 problems once in each of two blocks. The order of the problems in each block was randomly determined. The experts were called $\mathrm{A}$ and $\mathrm{B}$ in the first block and $\mathrm{C}$ and $\mathrm{D}$ in the second block. The other forty participants were assigned to Condition EV-wins-more that used the same procedure. The instructions and screens were the same as in Study 1 (recall Figure 1).

\section{Results}

The lower row in Table 7 presents the aggregate choice rates (and SM 3 presents the choice rates by problem). In accordance to the predictions of the reliance on small samples hypothesis, the choice rate of the option suggested by Expert Median (the option with higher Median) was higher than $50 \%$ in Condition Median-wins-more $(\mathrm{M}=0.55, \mathrm{SD}=0.15, \mathrm{t}(39)=1.99, \mathrm{p}=0.054)$, and significantly lower than 50\% in Condition EV-wins-more $(\mathrm{M}=0.40, \mathrm{SD}=0.14, \mathrm{t}(39)=4.29$, $\mathrm{p}<0.001)$. The difference between the two conditions is significant $(\mathrm{t}(78)=4.42, \mathrm{p}<0.001$, Cohen's $\mathrm{d}=0.99)$.

The left-hand graph of Figure 4 shows the mean choice rates in 20 blocks of 10 trials. The results reveal a relatively flat curve in Condition EV-wins-more, and fast initial adjustment in Condition Median-wins-more. Under one explanation of the difference between the two 
conditions, it reflects an initial tendency to prefer the option suggested by the average of the two experts, and an increase in the tendency to follow the expert that wins more with time. The flat learning curves in Condition EV-wins more can be the product of the fact that in this condition, the prescription of the average rule was similar to the prescription of the expert that wins more. When the expert that wins more disagrees with the average (only in Condition Median-wins-more), the results reveal a clear increase in the tendency to follow the expert that wins more. The right-hand graph presents the model predictions described below.

Figure 4. Study 3: Mean Choice Rates and Model's Predictions
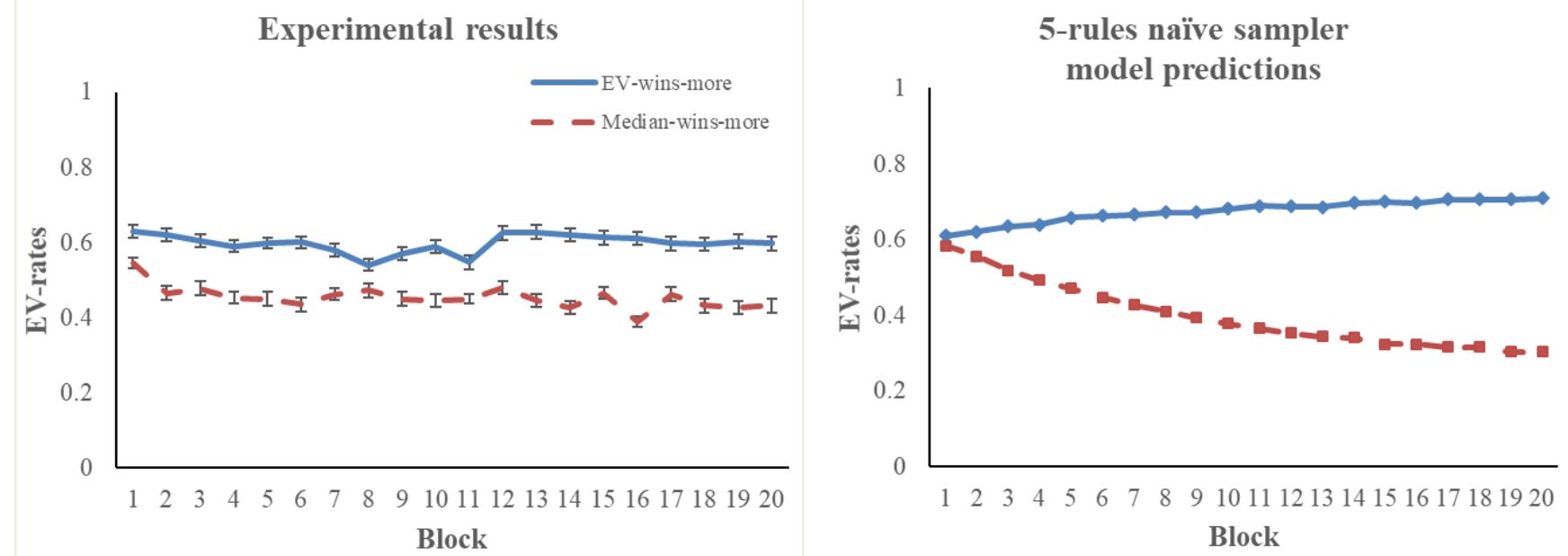

Note. Mean choice rates of the option with the higher valuation according to each of the two experts (EV and Median) (Left) and the "5-rules naïve sampler" model predictions described below (Right).

Individual differences. Table 8 presents the choice rates consistent with four of the rules described in Table 3 (the average rule was omitted as its prescription, in the current study, is always identical to the prescription of the EV rule). The results reveal two differences from the pattern documented in Studies 1 and 2: Larger individual differences and more subjects that are best described by rules Safe or Risk. Specifically, the proportion of subjects best described by rules Safe or Risk is 0.33 (10/30) in Study 1, 0.40 (16/40) in Study 2, and 0.64 (51/80) in the current study. Under one explanation of the current increase, many participants in Study 3 stopped trusting the experts and just chose a side (see related observation in Ecken \& Pibernik, 2015). There are at least two good reasons to stop trusting the experts in Study 3: They always contradict each other, and they are almost never accurate (the probability that the final outcome will be identical to the valuation is close to zero). 
Table 8. The Proportion of Choices Consistent With Four Distinct Rules by Condition and Participant

\begin{tabular}{|c|c|c|c|c|c|c|c|c|c|}
\hline \multicolumn{5}{|c|}{ EV-wins-more } & \multicolumn{5}{|c|}{ Median-wins-more } \\
\hline Participant number & EV & Med & Safe & Risk & Participant number & EV & Med & Safe & Risk \\
\hline 1 & 0.84 & 0.17 & 0.49 & 0.52 & 41 & 0.47 & 0.54 & 0.80 & 0.20 \\
\hline 2 & 0.93 & 0.08 & 0.52 & 0.48 & 42 & 0.50 & 0.50 & 0.88 & 0.13 \\
\hline 3 & 0.76 & 0.25 & 0.54 & 0.46 & 43 & 0.51 & 0.49 & 0.02 & 0.99 \\
\hline 4 & 0.59 & 0.42 & 0.35 & 0.65 & 44 & 0.46 & 0.55 & 0.40 & 0.61 \\
\hline 5 & 0.86 & 0.14 & 0.51 & 0.50 & 45 & 0.51 & 0.50 & 1.00 & 0.01 \\
\hline 6 & 0.63 & 0.38 & 0.14 & 0.86 & 46 & 0.49 & 0.51 & 0.73 & 0.27 \\
\hline 7 & 0.72 & 0.28 & 0.47 & 0.53 & 47 & 0.41 & 0.59 & 0.38 & 0.63 \\
\hline 8 & 0.52 & 0.49 & 0.39 & 0.61 & 48 & 0.50 & 0.50 & 0.53 & 0.47 \\
\hline 9 & 0.78 & 0.22 & 0.38 & 0.63 & 49 & 0.53 & 0.47 & 0.51 & 0.49 \\
\hline 10 & 0.51 & 0.50 & 1.00 & 0.01 & 50 & 0.51 & 0.49 & 0.79 & 0.21 \\
\hline 11 & 0.46 & 0.55 & 0.32 & 0.69 & 51 & 0.45 & 0.56 & 0.46 & 0.55 \\
\hline 12 & 0.68 & 0.32 & 0.79 & 0.22 & 52 & 0.17 & 0.83 & 0.45 & 0.56 \\
\hline 13 & 0.52 & 0.48 & 0.54 & 0.46 & 53 & 0.23 & 0.77 & 0.36 & 0.64 \\
\hline 14 & 0.49 & 0.51 & 0.83 & 0.17 & 54 & 0.54 & 0.47 & 0.51 & 0.50 \\
\hline 15 & 0.56 & 0.44 & 0.71 & 0.29 & 55 & 0.57 & 0.44 & 0.69 & 0.32 \\
\hline 16 & 0.89 & 0.11 & 0.46 & 0.55 & 56 & 0.56 & 0.45 & 0.42 & 0.58 \\
\hline 17 & 0.57 & 0.43 & 0.49 & 0.51 & 57 & 0.50 & 0.51 & 0.01 & 1.00 \\
\hline 18 & 0.50 & 0.51 & 0.62 & 0.38 & 58 & 0.07 & 0.94 & 0.47 & 0.54 \\
\hline 19 & 0.45 & 0.55 & 0.42 & 0.58 & 59 & 0.49 & 0.51 & 0.34 & 0.67 \\
\hline 20 & 0.53 & 0.47 & 0.50 & 0.50 & 60 & 0.55 & 0.45 & 0.58 & 0.43 \\
\hline 21 & 0.47 & 0.53 & 0.64 & 0.36 & 61 & 0.13 & 0.87 & 0.51 & 0.50 \\
\hline 22 & 0.57 & 0.43 & 0.40 & 0.60 & 62 & 0.51 & 0.49 & 0.94 & 0.06 \\
\hline 23 & 0.92 & 0.08 & 0.44 & 0.57 & 63 & 0.50 & 0.51 & 0.10 & 0.90 \\
\hline 24 & 0.49 & 0.51 & 0.53 & 0.48 & 64 & 0.58 & 0.42 & 0.50 & 0.51 \\
\hline 25 & 0.46 & 0.54 & 0.42 & 0.59 & 65 & 0.50 & 0.50 & 0.49 & 0.52 \\
\hline 26 & 0.49 & 0.51 & 1.00 & 0.00 & 66 & 0.62 & 0.39 & 0.38 & 0.63 \\
\hline 27 & 0.51 & 0.50 & 0.71 & 0.29 & 67 & 0.57 & 0.44 & 0.70 & 0.30 \\
\hline 28 & 0.48 & 0.53 & 0.54 & 0.46 & 68 & 0.52 & 0.49 & 0.61 & 0.39 \\
\hline 29 & 0.71 & 0.29 & 0.38 & 0.63 & 69 & 0.07 & 0.94 & 0.49 & 0.51 \\
\hline 30 & 0.55 & 0.45 & 0.52 & 0.48 & 70 & 0.58 & 0.43 & 0.42 & 0.58 \\
\hline 31 & 0.52 & 0.49 & 0.28 & 0.73 & 71 & 0.47 & 0.54 & 0.72 & 0.28 \\
\hline 32 & 0.52 & 0.49 & 0.28 & 0.73 & 72 & 0.54 & 0.46 & 0.86 & 0.15 \\
\hline 33 & 0.55 & 0.45 & 0.22 & 0.79 & 73 & 0.08 & 0.92 & 0.50 & 0.50 \\
\hline 34 & 0.45 & 0.56 & 0.09 & 0.91 & 74 & 0.48 & 0.53 & 0.50 & 0.51 \\
\hline 35 & 0.51 & 0.50 & 0.01 & 0.99 & 75 & 0.51 & 0.49 & 0.28 & 0.73 \\
\hline 36 & 0.49 & 0.52 & 0.56 & 0.44 & 76 & 0.53 & 0.47 & 0.21 & 0.79 \\
\hline 37 & 0.55 & 0.46 & 0.89 & 0.12 & 77 & 0.45 & 0.56 & 0.80 & 0.20 \\
\hline 38 & 0.80 & 0.20 & 0.44 & 0.57 & 78 & 0.49 & 0.51 & 0.22 & 0.78 \\
\hline 39 & 0.68 & 0.33 & 0.37 & 0.64 & 79 & 0.58 & 0.43 & 0.20 & 0.81 \\
\hline 40 & 0.50 & 0.51 & 1.00 & 0.01 & 80 & 0.50 & 0.50 & 0.23 & 0.78 \\
\hline Mean & 0.60 & 0.40 & 0.50 & 0.50 & & 0.44 & 0.56 & 0.51 & 0.49 \\
\hline \# best fitted & 15 & 1 & 10 & 14 & & 3 & 10 & 13 & 14 \\
\hline
\end{tabular}

Notes. 1 . The rules are described in Table 3; 2.0 .5 was rounded upward.

\section{Study 4}

The results presented above highlight the significance of two contributors to counterproductive use of valuations: The tendency to rely on small samples, and a tendency to follow the average valuation. In order to clarify the joint impact of the two contributors, Study 4 
takes the point of view of a policy maker who tries to reduce the impact of an expert that neglects rare events (and reports the median). Under the reliance on small samples hypothesis, the natural solutions involve mechanisms that increase the quality of the information available to decision makers. For example, the policy maker can increase the number of realizations drawn from the distributions valuated by the two experts. When the number of realizations is sufficiently large, selecting the option that maximizes EV also leads to the best outcome (averaged over all the realizations) in most cases. Thus, the decision makers are predicted to maximize EV even if they rely on small samples of past cases.

Under the "averaging" hypothesis, the easiest solution calls for exaggeration that reduces the accuracy of the information available to decision makers. Specifically, the policy maker can replace Expert EV with a biased expert providing more extreme valuations (in the same direction as Expert EV). When the bias is sufficiently large, it ensures that the average of the two experts' advice will favor the maximizing options. This easy solution, however, might backfire in the long run; the tendency to trust the exaggerating expert might decrease with experience.

To examine the joint impact of the two solutions, the current study uses a $2 \times 2$ betweensubjects experimental design described in Table 9. The members of Group Calibrated1 faced a replication of Study 1. Group Biased1 faced a variant in which Expert EV was replaced by a biased expert. The valuation of the risky prospect by the biased expert had the same sign as the prospect's $\mathrm{EV}$, and its absolute value was the prospect's median +1 . The valuation of the status quo was unbiased. Group Calibrated 100 faced a variant in which the feedback after each choice was 100 realizations drawn from the payoff distributions (see example in Figure 5), and Group Biased100 faced a variant with both modifications. The probability that the EV maximizing option led to a positive outcome (and following Expert EV minimized the probability of regret), in a random trial, was 0.11 given one realization, and 0.80 over 100 realizations.

\section{Table 9. Study 4: Experimental Design Summary and Mean Maximization Rates}

\begin{tabular}{|l|c|c|}
\hline $\begin{array}{l}\text { Feedback Type / } \\
\text { Expert Type }\end{array}$ & $\begin{array}{c}\text { Accurate (original } \\
\text { Expert EV) }\end{array}$ & $\begin{array}{c}\text { Biased (replacing Expert EV with a } \\
\text { more extreme Expert) that reports: } \\
\text { Sign(EV)[Abs(Median)+1] }\end{array}$ \\
\hline One realization & Calibrated1 & Biased1 \\
& $0.22(0.15)$ & $0.37(0.19)$ \\
\hline 100 Realizations & Calibrated100 & $0.89(0.15)$ \\
\hline
\end{tabular}

Notes. $\operatorname{Sign}(\mathrm{EV})=-1$ if $\mathrm{EV}<0,0$ if $\mathrm{EV}=0$, and +1 if $\mathrm{EV}>0 . \mathrm{Abs}(\mathrm{x})$ is the absolute value of $\mathrm{x}$. The numerical entries present the mean (and standard deviations) of the maximization rates. 
Figure 5. The Main Screens in Condition Calibrated100 of Study 4

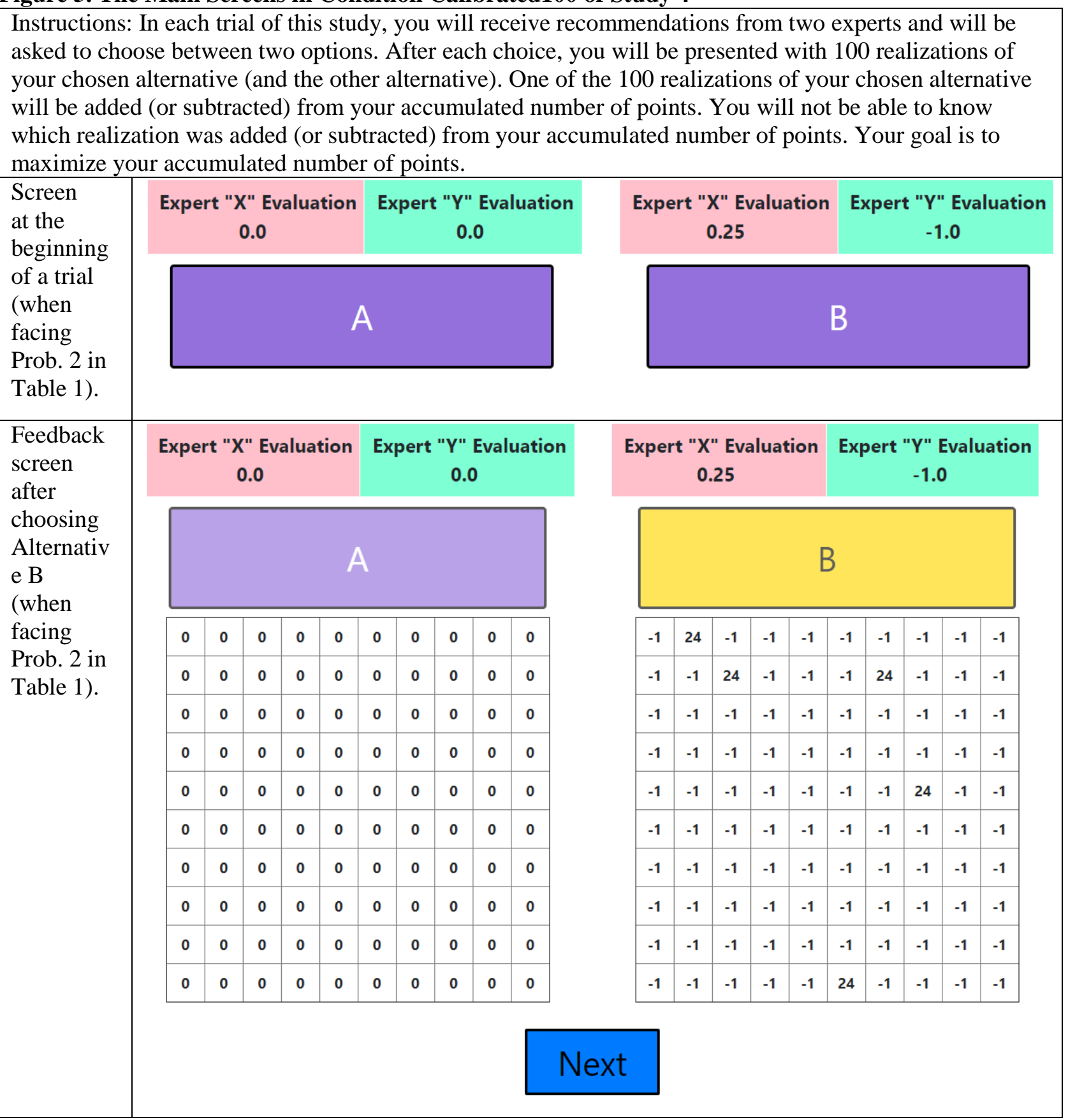

Participants. 171 Amazon Mechanical Turk (MTurk) workers took part in the study programmed with OTree (Chen et al., 2016) in exchange for a $\$ 0.50$ show-up fee and the chance to earn an additional bonus of $\$ 1$. As in Study 1, participants were told that the probability of a bonus increases with the number of points they earn. The experiment took about 6 minutes and the mean final payoff was about $\$ 1.31$ ( $\mathrm{SD}=0.4$ ). Our initial plan was to run 30 participants per condition 
(as in Study 1). Due to technical error ${ }^{5}$, we ran 31, 51, 30 and 59 participants in Groups Calibrated1, Biased1, Calibrated100 and Biased100, respectively. Analyzing the data based on the first 30 participants in each condition does not change the results in any meaningful way.

Procedure. The experimental procedure in Group Calibrated1 was identical to the procedure used in Study 1. The procedure in Group Biased1 was similar, but replaced Expect EV with the biased expert. The procedure in the two "100" groups was identical to the corresponding " 1 " groups, with the exception of the feedback and the implied addition to the instructions (see Figure 5). The participants were informed that the payoff of each trial would be one (randomly selected) of the 100 realizations.

\section{Results}

The numerical entries in Table 9 present the mean choice rates (and the standard deviations) of the expected value maximizing option (choices in accordance with Expert EV or the biased expert) in the four conditions (SM 4 presents the data by problem). The results reveal a significant interaction $\left(\chi^{2}(1)=9.47, p<0.001\right)$, and two significant main effects. First, over the four groups, improving the feedback by increasing the number of realizations from 1 to 100 increased the mean maximization rate from $34 \%$ to $66 \%\left(\chi^{2}(1)=130.71, p<0.001\right)$. Similarly, exaggeration (biasing Expert EV) increased the mean maximization rate from $31 \%$ to $77 \%$ $\left(\chi^{2}(1)=52.65, p<0.001\right)$. To our surprise, the interaction suggests a synergistic effect: increasing the number of realizations, enhanced the positive effect of exaggeration. The effect was $15 \%$ (an increase from $22 \%$ to $37 \%$, Cohen's $\mathrm{d}=0.85$ ) given one realization, and $34 \%$ (an increase from $55 \%$ to $89 \%$, Cohen's $d=1.68$ ) given 100 realizations.

The left-hand side of Figure 6 presents the maximization-rates in 10 blocks of 10 trials for each of the four conditions (the right-hand side of Figure 6 presents the predictions of the post-hoc model discussed below). It reveals a three-way (feedback type x expert type $\mathrm{x}$ time) interaction $\left(\chi^{2}(1)=11.90, p<0.001\right)$. This interaction suggests that the impact of the exaggeration was sensitive to the proportion of trials in which the feedback reveals that following the exaggerating expert led to the best outcome. When this proportion was low (0.11 in Condition Biaed 1$)$, the tendency to trust the exaggerating expert decreased with time. However, when this proportion was

\footnotetext{
${ }^{5}$ We initially run about 30 participants in conditions Biased 1 and Biased 100. Then instead of running the other two conditions, we mistakenly run all four conditions.
} 
high (0.80 in Condition Biaed100), the tendency to trust the exaggerating expert increased with time.

Figure 6. Study 4: Mean Choice Rates and the Model Predictions
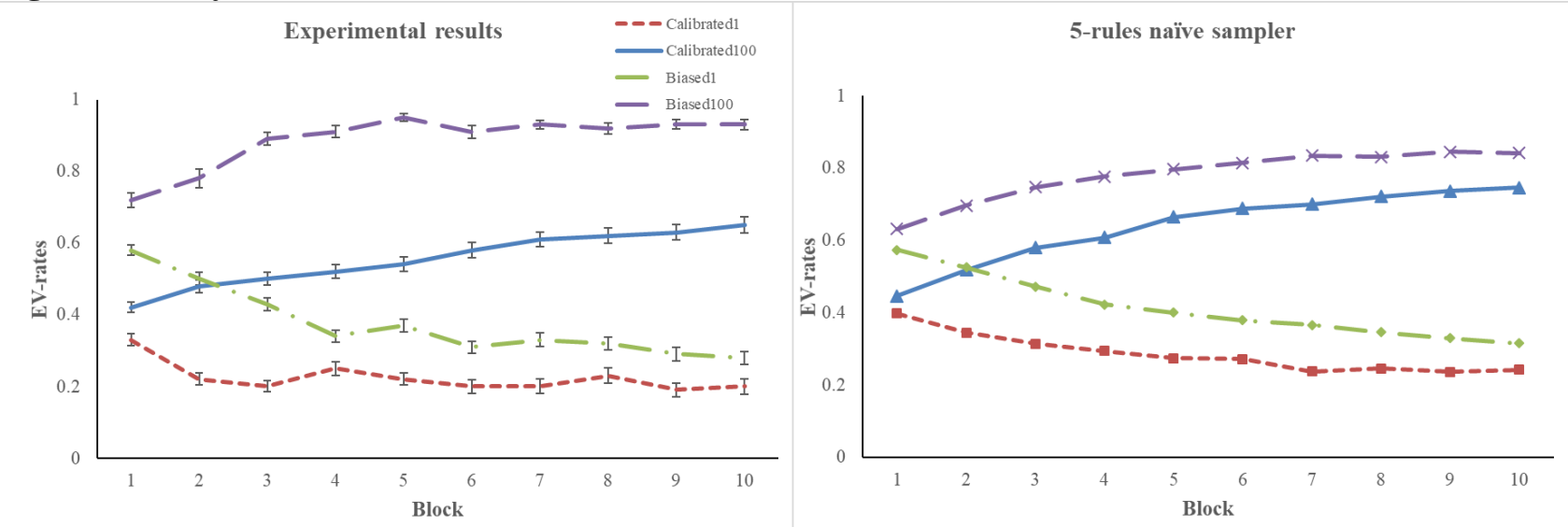

Notes. Mean choice rates of the expected value maximizing option in 10 blocks of 10 trials (Left), and the predictions of the "5-rules naïve sampler" model described below (Right).

Table 10 presents the proportion of participants whose choices are best fitted with the five decision rules described above (SM 5 presents the fit for each of the 171 participants). The results reveal large differences between the groups. Under one explanation, this suggests that the underlying processes are affected by the feedback. That is, participants behave as though they learn between rules.

Table 10. Study 4: Proportions of Participants Best Fitted With Five Distinct Rules by Group

\begin{tabular}{cccccc}
\hline $\begin{array}{c}\mathrm{X} \\
\text { (rule name) }\end{array}$ & $\begin{array}{c}\text { Higher } \\
\text { non-median } \\
\text { (EV or } \\
\text { exaggerating) }\end{array}$ & $\begin{array}{c}\text { Higher } \\
\text { median } \\
\text { (Median) }\end{array}$ & $\begin{array}{c}\text { Higher average } \\
\text { of the two } \\
\text { experts } \\
\text { (Average) }\end{array}$ & $\begin{array}{c}\text { Smaller } \\
\text { difference } \\
\text { between the two } \\
\text { experts } \\
\text { (Safe) }\end{array}$ & $\begin{array}{c}\text { Larger difference } \\
\text { between the two } \\
\text { experts } \\
\text { (Risk) }\end{array}$ \\
\hline Calibrated1 & 0.00 & 0.68 & 0.42 & 0.03 & 0.16 \\
Biased1 & 0.12 & 0.46 & 0.12 & 0.16 & 0.32 \\
Calibrated100 & 0.39 & 0.14 & 0.14 & 0.06 & 0.37 \\
Biased100 & 0.90 & 0.00 & 0.90 & 0.00 & 0.10 \\
\hline
\end{tabular}

\section{Implications to models of decisions from experience}

In order to clarify the implications of the current experimental results, we chose to examine which assumptions should be added to the basic generalization of the naïve sampler model (illustrated in Table 1) in order to capture the main findings. The simplest abstraction we could find, referred to as the "5-rules naïve sampler model" (5-rules for short), adds three assumptions. 
The first abstracts the set of rules considered by the decision makers, and was introduced to capture the observation that some participants appear to select the option with the higher average valuation, and others appear to select the safer or, the riskier option (Tables 3, 6, 8, and 10). While the basic model assumes learning between two rules ("Trust Expert Left" and "Trust Expert Right"), the results suggest that the decision makers behaved as though they considered the five rules described in these tables. 6

The second addition abstracts the way decision makers choose between the rules, and was introduced to capture the relative slow learning processes presented on the left-hand side of Figures 2, 3, 4, and 6. While the basic model assumes that both experts are considered in all trials, the results suggest diminishing exploration. Specifically, the added assumption implies an " $\varepsilon$-ignoring" choice between the rules. ${ }^{7}$ It states that the decision in trial $\mathrm{t}$ (in an experiment with $\mathrm{T}$ trials) starts by considering one randomly selected option, and then considers each of the other options with probability $1-\varepsilon^{(t-1) /(T-1)}$ where $\varepsilon$ is a free parameter that captures a tendency to ignore rules. Thus, the probability of considering each of the other rules increases with $\mathrm{t}$. The algorithm that captures the selection between the considered rules was not modified: in trial $t$, the decision makers recall $\kappa$ previous trials (with replacement from all previous trials, not just the last $\kappa$ ) and select the rule that leads to the best average payoff in this sample (among the rules they consider).

The third addition involves the abstraction of observing multiple outcomes. While the basic model assumes reliance on small samples of outcomes, the added assumption implies that the experience associated with observing 100 realizations in the same trial is their expected value (but replacing this assumption with a noisy estimation of the EV, as in Luria, Erev \& Haruvy, 2017, does not change the predictions if the noise does not change the sign of the estimate). That is, the model assumes that these 100 observations are summarized in memory as one number.

The extended model has two free parameters: к and $\varepsilon$. Appendix 1 presents a numerical example that clarifies the assumed processes. The right-hand curves in Figures 2, 3, 4 and 6 present the predictions of the 5-rules model for the current experiments with the parameters that best fit the data $(\kappa=3, \varepsilon=0.25)$. The fit was quantified with the Mean Squared Distance (MSD) between the

\footnotetext{
${ }^{6}$ Notice that in the current context rule "Safe" can also be called "Maximin" (selecting it implies maximizing the worst payoff), and rule "Risk" can also be called "Maximax" (selecting it maximizes the best possible payoff).

${ }^{7}$ We also considered the simpler $\varepsilon$-greedy choice algorithm (assuming selection of the rule with the highest average in the sample with probability $1-\varepsilon$, and random choice otherwise), but with this algorithm the model cannot capture the synergistic interaction.
} 
observed and the predicted (reproduced) EV-rates and Median-rates over the data (in blocks of 10 trials and giving the same weight to each of the distinct conditions). The obtained MSD score was 0.0063. The right-hand sides of Figures 2, 3, 4, and 6 show that the model captures the main results: a decline in maximization rate in Study 1, a relatively stable preference for Expert Median in Study 2, initial tendency to follow Expert EV in Condition Median-wins-more of Study 3, and synergistic interaction in Study 4. The reproduction of the flatter curves in Study 2 reflects the fact that in this study the experts favor the same option in most cases, and as a result, the reliance on small sample process often implies random choice between EV, Median and Average.

To quantify the value of each of the three added assumptions we also fitted variants of the 5-rules model that eliminate each assumption. Elimination of the three added rules (assuming learning between "Trust Expert Left" and "Trust Expert Right") increases the MSD score to 0.022 (and eliminates the fit of the positive impact of exaggeration on maximization). Elimination of the diminishing exploration assumption (the constraint $\varepsilon=0$ ) increases the MSD score to 0.013 (with $\kappa=1$, which minimizes the MSD in this case). Elimination of the assumed sensitivity to the EV of the observed realizations in each trial (the 100 observations in "100" conditions of Study 4) increases the MSD score to 0.042 (with $\kappa=18$, and $\varepsilon=0.6$ ) and eliminates the fit of the positive impact of increasing the number of realizations on maximization.

It is possible, of course, to find more complex models that will fit the data better than the 5rules model. For example, it is likely that people consider more rules. In addition, better abstraction of the sampling process can improve the fit of the individual differences. The current model assumes independent random draw of $\kappa$ past experience before each choice, and underpredicts the magnitude of the individual difference. Relaxing the independence part of this assumption, by allowing inertia (using the same sample in multiple trials that implies inertia, see Nevo \& Erev, 2012), improves the fit of the individual differences pattern without impairing the fit of the aggregate choice rate.

The main contribution of the current modeling exercise is the demonstration of a sufficient condition to our main results, and further, that it is not easy to find simpler abstraction. In addition, it suggests that in order to generalize models designed to capture abstract choice tasks (like the naïve sampler model) to more complex environments, it is useful to add abstractions that capture three aspects of the decision process: the feasible rules, the nature of the exploration, and the summary of multiple outcomes. 


\section{General Discussion}

The current investigation clarifies the impact of experience on the way people use valuations. The first two studies demonstrate that experience can increase the tendency to follow valuations provided by "experts" that ignore important rare outcomes (and reports the median/mode of the outcomes' distributions) and reduce the tendency to follow well-calibrated experts that recommend the actions that maximize expected return. For example, in Study 1, experience with decisions between the status quo and distinct binary lotteries increased the tendency to select the lottery when an expert reporting its median (that equaled the mode) provided a positive valuation, even when an expert reporting its EV provided a negative valuation. Study 2 shows similar results in choices between more complex prospects. Study 3 demonstrates a tendency to trust experts that recommend the best choice in most trials even when these experts do not report the median or the mode of the distributions.

Study 4 illustrates the joint impact of the two contributors to the inclination to trust expert valuations that ignore rare events, and also sheds light on two methods that can be used to reduce this bias. The two contributors involve a tendency to rely on small samples of past experience, and a tendency to average the experts' valuations. The first method increases the quality of the feedback available to the decision makers to reduce the impact of reliance on small samples. The second method replaces the well-calibrated EV valuations with exaggerated valuations (in the same direction as the EV) to decrease the negative impact of the tendency to average the valuations. The results show that the impact of exaggerating, without improving the quality of the feedback, diminishes with time. However, when the feedback is improved to ensure that the EV maximizing option leads to the best feedback in most trials, experience did not decrease the tendency to follow the exaggerating expert; indeed, this tendency increased with experience.

In order to clarify the relationship between the current results and Bolton and Katok's (2018) analysis that has motivated our investigation, it is important to note that Bolton and Katok focused on the impact of the expert's credibility (and calibration) while controlling for the implied recommendation (for EV maximizing decision makers). Moreover, in their experiment, the choices that maximized EV also led to the best outcomes in most cases. Their results show that in this setting, experience leads decision makers to trust the well-calibrated experts. Our results do not question the replicability of their finding, but suggest that when comparing experts that provide different recommendations, the decision makers are more sensitive to the outcomes of the 
recommended choices than to the experts' calibration. In addition, our results highlight two properties of the way people react to the outcomes that can lead them to ignore the well-calibrated source: reliance on small samples, and averaging the different experts.

The wider theoretical implications of the current analysis involve the generalization of basic decision-making research to situations in which decision makers must learn how to make the best use of available information (in our setting, the valuations, and obtained outcomes). Our results highlight similarities and differences between the effects of experience in basic choice tasks and the effects of experience in the current more complex setting. A key similarity involves the descriptive value of the reliance on small samples hypothesis. As in basic studies of decisions from experience, the main effect of experience in decisions from valuation, examined here, is consistent with the assumption that decision makers tend to rely on small samples of past experiences. The main difference, on the other hand, involves the strategies that the decision makers appear to consider during the learning process. Whereas the effect of experience in basic choice tasks can be captured by assuming learning between the feasible actions (e.g., the two keys in the basic clicking paradigm), the effect of experience on decisions from valuation appears to reflect learning from a larger set of strategies. Our analysis suggests that the decision makers considered at least five rules: follow Expert Left, follow Expert Right, follow the average of the two experts, select the safer option (the one on which the two experts agree), and select the riskier option (the one on which the two experts disagree).

These observations highlight the value of decomposing the abstraction of the effect of experience on choice behavior to two sub-models: the abstraction of the cognitive strategies considered by the decision maker and the abstraction of the way decision makers choose between the different strategies. Our results suggest that while the "cognitive strategies" sub-model is likely to reflect specific features of the environment, the "choice among strategies" sub-model might reflect a general decision process. Specifically, the choice process in both basic decisions from experience and the current decisions from valuations can be captured by assuming reliance on small samples of past experience. In that respect, the current analysis refines the analysis presented by Erev and Roth, (1999) and Rieskamp and Otto, (2006). These studies assume reinforcement learning among cognitive strategies, and the current analysis suggests that learning among cognitive strategies can be captured by the simpler reliance on small samples assumption. 
The direct practical implication of the current analysis includes the clarification of two related problems. First, the results suggest that designers of expert systems can increase the system's popularity by biasing the valuation in favor of the option that leads to the best outcome in most cases, even if this bias impairs the users' expected return. In other words, competition among the developers of expert systems does not guarantee an increase in accuracy (see related observation in Radzevick \& Moore, 2011).

A second problem involves the weighting of rare events. The current analysis suggests that reliance on valuations can reduce sensitivity to rare events and, for that reason, enhance the "black swan" effect (Taleb, 2007). Previous experimental studies of this effect suggest that it can be the product of the tendency to rely on small samples that imply low probability of considering rare events, and doubting the description of these events (Marchiori, DiGuida \& Erev, 2015). The current results add the observation that in certain settings experts that try to increase their number of followers, are motivated to report valuations that ignore rare events even after considering these events.

While the current analysis focuses on small decisions (low payoff magnitude) which simulate the use of automatic "expert systems" such as Google Maps and Waze, it is possible that certain big decisions reflect a similar bias. Indeed, it is natural to assume that one of our main results, the higher sensitivity to the payoff from trusting the valuations than to the experts' calibration, is likely to increase with payoff magnitude. In order to clarify the potential implications of this observation we chose to conclude with a discussion of two important examples: The tendency to trust experts that underweight the risk associated with global warming and Covid-19, and doubt the valuations supported by careful scientific research. The natural efforts to reduce this tendency try to clarity the higher accuracy of the scientific valuations. The current analysis suggests that it is also important to increase the probability that trusting the scientific valuations is rewarding. ${ }^{8}$ For example, the tendency to pollute and ignore the risks associated with global warming can be addressed by taxing polluting products. Similarly, the tendency to underweight the risk associated by Covid-19 can be addressed by using vaccination certificates that help vaccinated individuals skip time consuming tests (see Plonsky, Roth \& Erev, 2021).

\footnotetext{
${ }^{8}$ Notice that the method used to increase the probability that trusting the maximization expert is rewarding in Study 4 , cannot be used here. In the current natural examples, it is not possible to increase the number of realizations that determine the outcomes of each choice.
} 
To conclude, the current investigation of decisions from valuations of unknown payoff distributions highlights three main observations: First, experience can decrease the trust in wellcalibrated sources of information. Second, the negative impact of experience we observed can be explained as the product of two tendencies: reliance on small samples of past experiences that implies an inclination to trust experts who ignore rare events, and a tendency to average the valuation provided by the different experts, which implies higher sensitivity to the more extreme valuations. Finally, experts that direct people toward the optimal choice can increase their impact by exaggerating. However, the long-term impact of exaggeration depends on the proportion of cases in which the optimal choice leads to the best payoff; lasting positive effect of exaggeration was observed only when this proportion was high.

\section{Acknowledgments}

This research was supported by a grant (no. 535/17) from the Israeli Science Foundation to Ido Erev. The authors thank Greta Mayan Waldman for useful suggestions and editorial assistance, and Yuval Shraiber for programming Study 4. 


\section{Appendix 1. Numerical Example of the Computations Assumed by the 5-rules Model:}

The current example focuses on the choice in trial 7, of an agent with $\kappa=3$, and $\varepsilon=0.2$, after experiencing the following six trials (in Study 1):

\begin{tabular}{|c|c|c|c|c|c|c|c|}
\hline Trial & $\begin{array}{l}\text { Left } \\
\text { Expert } \\
\text { EV }\end{array}$ & $\begin{array}{l}\text { Left } \\
\text { Expert } \\
\text { Median }\end{array}$ & $\begin{array}{l}\text { Right } \\
\text { Expert } \\
\text { EV }\end{array}$ & $\begin{array}{l}\text { Right } \\
\text { Expert } \\
\text { Median }\end{array}$ & $\begin{array}{l}\text { Left } \\
\text { Observed }\end{array}$ & $\begin{array}{l}\text { Right } \\
\text { Observed }\end{array}$ & $\begin{array}{l}\text { Agent's } \\
\text { Choices }\end{array}$ \\
\hline 1 & 0 & 0 & 0.3 & -0.9 & 0 & -0.9 & Left \\
\hline 2 & 0 & 0 & 0.4 & -0.8 & 0 & -0.8 & Right \\
\hline 3 & 0 & 0 & 0.5 & -0.7 & 0 & 5.3 & Right \\
\hline 4 & 0 & 0 & -0.54 & 1.1 & 0 & 1.1 & Left \\
\hline 5 & 0 & 0 & -0.6 & 1 & 0 & 1 & Left \\
\hline 6 & 0 & 0 & -0.66 & 0.9 & 0 & 0.9 & Right \\
\hline 7 & 0 & 0 & -0.82 & 0.8 & & & Right \\
\hline
\end{tabular}

Let's assume that the agent decides to consider "Rule EV" first.

The probability to consider each of the other rules is: $1-0.2^{(7-1) /(100-1)}=0.1$. Let's assume that the agent decides to consider "Rule Median" (in addition to Rule EV) and ignores the other three rules.

Let's further assume that the agent recalls trials $\{1,2$, and 5$\}$ (notice that the sample size is $\kappa=3$ ).

Now, the agent calculates the payoffs based on each of the considered rules (EV and Median) in her recalled sample:

- $\mathrm{EV}=[-0.9-0.8+0] / 3=-0.57$

Explanation: Expert EV favors (provides positive valuation) Right (the risky lottery) in Trials 1 and 2, and favors the Left (status quo) in Trial 5.

- $\operatorname{Median}=[0+0+1] / 3=+0.33$

In the recalled sample, among the considered rules the highest mean payoff is from Rule Median, and the predicted choice in trial 7 is Right (as the valuation of Expert Median in Trial 7 is positive (0.8)). 


\section{References}

Allais, M. (1953). Le comportement de l'homme rationnel devant le risque: critique des postulats et axiomes de l'école américaine. Econometrica: Journal of Econometric Society, 21(4), 503-546. JOUR. https://doi.org/10.2307/1907921

Ariely, D., Tung Au, W., Bender, R. H., Budescu, D. V., Dietz, C. B., Gu, H., Walsten, T. S. \& Zauberman, G. (2000). The effects of averaging subjective probability estimates between and within judges. Journal of Experimental Psychology: Applied, 6(2), 130-147.

Benjamin, D, \& Budescu, DV. (2015). Advice from experience: Communicating incomplete information incompletely. J. Behav. Decision Making, 28(1), 36-49.

Brier, GW. (1950). Verification of forecasts expressed in terms of probability. Monthey Weather Rev. 78(1):1-3.

Bolton G, \& Katok E (2018) Cry wolf or equivocate? Credible forecast guidance in a cost-loss game. Management Science, 64(3), 1440-1457.

Bonaccio S, \& Dalal RS (2006) Advice taking and decision-making: An integrative literature review, and implications for the organizational sciences. Organizational Behavior Human Decision Processes, 101(2),127-151.

Broomell, S., Budescu, D.V., \& Por H. (2011). Pair-wise comparisons of multiple models. Judgment and Decision Making, 6, 820-830.

Cabantous, L., Hilton, D., Kunreuther, H., \& Michel-Kerjan E. (2011). Is imprecise knowledge better than conflicting expertise? Evidence from insurers' decisions in the United States. Journal of Risk and Uncertainty, 42(3),211232.

Chen, D. L., Schonger, M., \& Wickens, C. (2016). oTree-An open-source platform for laboratory, online, and field experiments. Journal of Behavioral and Experimental Finance, 9, 88-97.

Cohen, D., Plonsky, O., \& Erev, I. (2020). On the impact of experience on probability weighting in decisions under risk. Decision, 7(2), 153-162.

Dietvorst, BJ., \& Bharti, S. (2020). People reject algorithms in uncertain decision domains because they have diminishing sensitivity to forecasting error. Psychological Science, 31(10), 1302-1314.

Erev, I., \& Cohen BL. (1990). Verbal versus numerical probabilities: Efficiency, biases, and the preference paradox. Organizational Behaviour Human Decision Processes, 45(1), 1-18.

Erev, I., Ert E, Plonsky O, Cohen D, \& Cohen O. (2017). From anomalies to forecasts: Toward a descriptive model of decisions under risk, under ambiguity, and from experience. Psychological Review, 124(4),369-409.

Erev, I., Ert, E., \& Roth, A. E. (2010). A choice prediction competition for market entry games: An introduction. Games, 1(2), 117-136. https://doi.org/10.3390/g1020117

Erev, I., Ert, E., Roth, A. E., Haruvy, E., Herzog, S. M., Hau, R., Hertwig, R., Stewart, T., West, R., \& Lebiere, C. (2010). A choice prediction competition: Choices from experience and from description. Journal of Behavioral Decision Making, 23(1), 15-47. https://doi.org/10.1002/bdm.683

Erev, I., \& Haruvy, E. (2016). Learning and the economics of small decisions. Handbook of Experimental Economics, 2, 9781400883172--011. 
Erev, I., Plonsky, O., \& Roth, Y. (2020). Complacency, panic, and the value of gentle rule enforcement in addressing pandemics. Nature Human Behavior, 4, 1095-1097. https://doi.org/10.1038/s41562-020-00939-z

Erev, I., \& Roth, AE. (1999). On the role of reinforcement learning in experimental games: The cognitive gametheoretic approach.

Erev, I., \& Roth AE. (2014). Maximization, learning, and economic behavior. Proceeding of National Academy of Science 111(Supplement 3):10818-10825.

Harries, C., Yaniv, I., \& Harvey, N. (2004). Combining advice: The weight of a dissenting opinion in the consensus. Journal of Behavioral Decision Making, 17(5), 333-348.

Hertwig, R., \& Erev, I. (2009). The description--experience gap in risky choice. Trends in Cognitive Science, 13(12): 517-523.

Kahneman, D, \& Tversky A. (1979). Prospect Theory: An Analysis of Decision under Risk. Econometrica, 47(2), 263292.

Larrick, RP, \& Soll JB. (2006). Intuitions about combining opinions: Misappreciation of the averaging principle. Management Science, 52(1), 111-127.

Luria, A., Erev, I., \& Haruvy, E. (2017). The reinforcing value of lottery tickets, and the synergetic effect of distinct reinforcements. Journal of Behavioral Decision Making, 30(2), 533-540.

Marchiori, D., Di Guida, S., \& Erev, I. (2015). Noisy retrieval models of over-and undersensitivity to rare events. Decision, 2(2), 82-106.

Plonsky, O., Apel, R., Ert, E., Tennenholtz, M., Bourgin, D., Peterson, J. C., Reichman, D., Griffiths, T. L., Russell, S. J., Carter, E. C., Cavanagh, J. F., \& Erev, I. (2019). Predicting human decisions with behavioral theories and machine learning. ArXiv Preprint ArXiv:1904.06866.

Plonsky, O., Roth, Y., \& Erev, I. (2021). Underweighting of rare events in social interactions and its implications to the design of voluntary health applications. Judgment and Decision Making, 16(2), 267-289.

Plonsky, O., Teodorescu, K., \& Erev, I. (2015). Reliance on small samples, the wavy recency effect, and similaritybased learning. Psychological Review, 122(4), 621-647.

Radzevick, JR., \& Moore, DA. (2011). Competing to be certain (but wrong): Social pressure and overprecision in judgment. Management Science, 57(1), 93-106.

Rieskamp, J., \& Otto, PE. (2006). SSL: a theory of how people learn to select strategies. Journal of Experimental Psychology: General, 135(2), 207-236.

Taleb, NN. (2007). The black swan: The impact of the highly improbable (Vol. 2). Random house.

Winkler, RL. (1969). Scoring rules and the evaluation of probability assessors. Journal of American Statistics Association, 64(327), 1073-1078.

Winkler, RL. (1981). Combining probability distributions from dependent information sources. Management Science, 27(4), 479-488. 


\section{Supplementary Material}

SM 1. Study 1: Problems and Choice Rates

\begin{tabular}{|c|c|c|c|c|c|c|c|c|}
\hline \multirow[b]{2}{*}{ Problem } & \multirow[b]{2}{*}{ Safe } & \multirow[b]{2}{*}{ Risk H } & \multirow[b]{2}{*}{$\mathrm{P}($ Risk H) } & \multirow[b]{2}{*}{ Risk L } & \multicolumn{2}{|c|}{ Valuations of risk } & \multicolumn{2}{|c|}{ Choice rates } \\
\hline & & & & & Expert EV & Expert Median & Risk & Median \\
\hline 1 & 0 & 24.1 & 0.05 & -1.1 & 0.16 & -1.1 & 0.3 & 0.7 \\
\hline 2 & 0 & 24 & 0.05 & -1 & 0.25 & -1 & 0.33 & 0.67 \\
\hline 3 & 0 & 23.9 & 0.05 & -0.9 & 0.34 & -0.9 & 0.23 & 0.77 \\
\hline 4 & 0 & 23.8 & 0.05 & -0.8 & 0.43 & -0.8 & 0.37 & 0.63 \\
\hline 5 & 0 & 23.7 & 0.05 & -0.7 & 0.52 & -0.7 & 0.37 & 0.63 \\
\hline 6 & 0 & 21.9 & 0.05 & -1.1 & 0.05 & -1.1 & 0.2 & 0.8 \\
\hline 7 & 0 & 22 & 0.05 & -1 & 0.15 & -1 & 0.23 & 0.77 \\
\hline 8 & 0 & 22.1 & 0.05 & -0.9 & 0.25 & -0.9 & 0.23 & 0.77 \\
\hline 9 & 0 & 22.2 & 0.05 & -0.8 & 0.35 & -0.8 & 0.33 & 0.67 \\
\hline 10 & 0 & 22.3 & 0.05 & -0.7 & 0.45 & -0.7 & 0.37 & 0.63 \\
\hline 11 & 0 & 17.1 & 0.07 & -1.1 & 0.174 & -1.1 & 0.23 & 0.77 \\
\hline 12 & 0 & 17 & 0.07 & -1 & 0.26 & -1 & 0.43 & 0.57 \\
\hline 13 & 0 & 16.9 & 0.07 & -0.9 & 0.346 & -0.9 & 0.27 & 0.73 \\
\hline 14 & 0 & 16.8 & 0.07 & -0.8 & 0.432 & -0.8 & 0.23 & 0.77 \\
\hline 15 & 0 & 16.7 & 0.07 & -0.7 & 0.518 & -0.7 & 0.27 & 0.73 \\
\hline 16 & 0 & 14.9 & 0.07 & -1.1 & 0.02 & -1.1 & 0.17 & 0.83 \\
\hline 17 & 0 & 15 & 0.07 & -1 & 0.12 & -1 & 0.37 & 0.63 \\
\hline 18 & 0 & 15.1 & 0.07 & -0.9 & 0.22 & -0.9 & 0.27 & 0.73 \\
\hline 19 & 0 & 15.2 & 0.07 & -0.8 & 0.32 & -0.8 & 0.27 & 0.73 \\
\hline 20 & 0 & 15.3 & 0.07 & -0.7 & 0.42 & -0.7 & 0.3 & 0.7 \\
\hline 21 & 0 & 13.1 & 0.1 & -1.1 & 0.32 & -1.1 & 0.33 & 0.67 \\
\hline 22 & 0 & 13 & 0.1 & -1 & 0.4 & -1 & 0.3 & 0.7 \\
\hline 23 & 0 & 12.9 & 0.1 & -0.9 & 0.48 & -0.9 & 0.27 & 0.73 \\
\hline 24 & 0 & 12.8 & 0.1 & -0.8 & 0.56 & -0.8 & 0.47 & 0.53 \\
\hline 25 & 0 & 12.7 & 0.1 & -0.7 & 0.64 & -0.7 & 0.17 & 0.83 \\
\hline 26 & 0 & 10.9 & 0.1 & -1.1 & 0.1 & -1.1 & 0.3 & 0.7 \\
\hline 27 & 0 & 11 & 0.1 & -1 & 0.2 & -1 & 0.27 & 0.73 \\
\hline 28 & 0 & 11.1 & 0.1 & -0.9 & 0.3 & -0.9 & 0.23 & 0.77 \\
\hline 29 & 0 & 11.2 & 0.1 & -0.8 & 0.4 & -0.8 & 0.27 & 0.73 \\
\hline 30 & 0 & 11.3 & 0.1 & -0.7 & 0.5 & -0.7 & 0.17 & 0.83 \\
\hline 31 & 0 & 9.1 & 0.15 & -1.1 & 0.43 & -1.1 & 0.2 & 0.8 \\
\hline 32 & 0 & 9 & 0.15 & -1 & 0.5 & -1 & 0.3 & 0.7 \\
\hline 33 & 0 & 8.9 & 0.15 & -0.9 & 0.57 & -0.9 & 0.33 & 0.67 \\
\hline 34 & 0 & 8.8 & 0.15 & -0.8 & 0.64 & -0.8 & 0.23 & 0.77 \\
\hline 35 & 0 & 8.7 & 0.15 & -0.7 & 0.71 & -0.7 & 0.4 & 0.6 \\
\hline 36 & 0 & 6.9 & 0.15 & -1.1 & 0.1 & -1.1 & 0.2 & 0.8 \\
\hline 37 & 0 & 7 & 0.15 & -1 & 0.2 & -1 & 0.23 & 0.77 \\
\hline 38 & 0 & 7.1 & 0.15 & -0.9 & 0.3 & -0.9 & 0.1 & 0.9 \\
\hline 39 & 0 & 7.2 & 0.15 & -0.8 & 0.4 & -0.8 & 0.23 & 0.77 \\
\hline 40 & 0 & 7.3 & 0.15 & -0.7 & 0.5 & -0.7 & 0.13 & 0.87 \\
\hline 41 & 0 & 7.1 & 0.2 & -1.1 & 0.54 & -1.1 & 0.3 & 0.7 \\
\hline 42 & 0 & 7 & 0.2 & -1 & 0.6 & -1 & 0.37 & 0.63 \\
\hline 43 & 0 & 6.9 & 0.2 & -0.9 & 0.66 & -0.9 & 0.4 & 0.6 \\
\hline 44 & 0 & 6.8 & 0.2 & -0.8 & 0.72 & -0.8 & 0.37 & 0.63 \\
\hline 45 & 0 & 6.7 & 0.2 & -0.7 & 0.78 & -0.7 & 0.4 & 0.6 \\
\hline 46 & 0 & 4.9 & 0.2 & -1.1 & 0.1 & -1.1 & 0.27 & 0.73 \\
\hline 47 & 0 & 5 & 0.2 & -1 & 0.2 & -1 & 0.17 & 0.83 \\
\hline 48 & 0 & 5.1 & 0.2 & -0.9 & 0.3 & -0.9 & 0.2 & 0.8 \\
\hline 49 & 0 & 5.2 & 0.2 & -0.8 & 0.4 & -0.8 & 0.17 & 0.83 \\
\hline 50 & 0 & 5.3 & 0.2 & -0.7 & 0.5 & -0.7 & 0.33 & 0.67 \\
\hline 51 & 0 & 1.1 & 0.8 & -7.1 & -0.54 & 1.1 & 0.7 & 0.7 \\
\hline 52 & 0 & 1 & 0.8 & -7 & -0.6 & 1 & 0.67 & 0.67 \\
\hline 53 & 0 & 0.9 & 0.8 & -6.9 & -0.66 & 0.9 & 0.7 & 0.7 \\
\hline 54 & 0 & 0.8 & 0.8 & -6.8 & -0.72 & 0.8 & 0.6 & 0.6 \\
\hline 55 & 0 & 0.7 & 0.8 & -6.7 & -0.78 & 0.7 & 0.43 & 0.43 \\
\hline 56 & 0 & 1.1 & 0.8 & -4.9 & -0.1 & 1.1 & 0.7 & 0.7 \\
\hline
\end{tabular}




\begin{tabular}{|c|c|c|c|c|c|c|c|c|}
\hline 57 & 0 & 1 & 0.8 & -5 & -0.2 & 1 & 0.67 & 0.67 \\
\hline 58 & 0 & 0.9 & 0.8 & -5.1 & -0.3 & 0.9 & 0.87 & 0.87 \\
\hline 59 & 0 & 0.8 & 0.8 & -5.2 & -0.4 & 0.8 & 0.73 & 0.73 \\
\hline 60 & 0 & 0.7 & 0.8 & -5.3 & -0.5 & 0.7 & 0.83 & 0.83 \\
\hline 61 & 0 & 1.1 & 0.85 & -9.1 & -0.43 & 1.1 & 0.73 & 0.73 \\
\hline 62 & 0 & 1 & 0.85 & -9 & -0.5 & 1 & 0.6 & 0.6 \\
\hline 63 & 0 & 0.9 & 0.85 & -8.9 & -0.57 & 0.9 & 0.63 & 0.63 \\
\hline 64 & 0 & 0.8 & 0.85 & -8.8 & -0.64 & 0.8 & 0.7 & 0.7 \\
\hline 65 & 0 & 0.7 & 0.85 & -8.7 & -0.71 & 0.7 & 0.7 & 0.7 \\
\hline 66 & 0 & 1.1 & 0.85 & -6.9 & -0.1 & 1.1 & 0.73 & 0.73 \\
\hline 67 & 0 & 1 & 0.85 & -7 & -0.2 & 1 & 0.77 & 0.77 \\
\hline 68 & 0 & 0.9 & 0.85 & -7.1 & -0.3 & 0.9 & 0.9 & 0.9 \\
\hline 69 & 0 & 0.8 & 0.85 & -7.2 & -0.4 & 0.8 & 0.87 & 0.87 \\
\hline 70 & 0 & 0.7 & 0.85 & -7.3 & -0.5 & 0.7 & 0.77 & 0.77 \\
\hline 71 & 0 & 1.1 & 0.9 & -13.1 & -0.32 & 1.1 & 0.63 & 0.63 \\
\hline 72 & 0 & 1 & 0.9 & -13 & -0.4 & 1 & 0.67 & 0.67 \\
\hline 73 & 0 & 0.9 & 0.9 & -12.9 & -0.48 & 0.9 & 0.7 & 0.7 \\
\hline 74 & 0 & 0.8 & 0.9 & -12.8 & -0.56 & 0.8 & 0.67 & 0.67 \\
\hline 75 & 0 & 0.7 & 0.9 & -12.7 & -0.64 & 0.7 & 0.63 & 0.63 \\
\hline 76 & 0 & 1.1 & 0.9 & -10.9 & -0.1 & 1.1 & 0.8 & 0.8 \\
\hline 77 & 0 & 1 & 0.9 & -11 & -0.2 & 1 & 0.77 & 0.77 \\
\hline 78 & 0 & 0.9 & 0.9 & -11.1 & -0.3 & 0.9 & 0.83 & 0.83 \\
\hline 79 & 0 & 0.8 & 0.9 & -11.2 & -0.4 & 0.8 & 0.87 & 0.87 \\
\hline 80 & 0 & 0.7 & 0.9 & -11.3 & -0.5 & 0.7 & 0.83 & 0.83 \\
\hline 81 & 0 & 1.1 & 0.93 & -17.1 & -0.174 & 1.1 & 0.67 & 0.67 \\
\hline 82 & 0 & 1 & 0.93 & -17 & -0.26 & 1 & 0.7 & 0.7 \\
\hline 83 & 0 & 0.9 & 0.93 & -16.9 & -0.346 & 0.9 & 0.7 & 0.7 \\
\hline 84 & 0 & 0.8 & 0.93 & -16.8 & -0.432 & 0.8 & 0.73 & 0.73 \\
\hline 85 & 0 & 0.7 & 0.93 & -16.7 & -0.518 & 0.7 & 0.73 & 0.73 \\
\hline 86 & 0 & 1.1 & 0.93 & -14.9 & -0.02 & 1.1 & 0.73 & 0.73 \\
\hline 87 & 0 & 1 & 0.93 & -15 & -0.12 & 1 & 0.67 & 0.67 \\
\hline 88 & 0 & 0.9 & 0.93 & -15.1 & -0.22 & 0.9 & 0.77 & 0.77 \\
\hline 89 & 0 & 0.8 & 0.93 & -15.2 & -0.32 & 0.8 & 0.77 & 0.77 \\
\hline 90 & 0 & 0.7 & 0.93 & -15.3 & -0.42 & 0.7 & 0.8 & 0.8 \\
\hline 91 & 0 & 1.1 & 0.95 & -24.1 & -0.16 & 1.1 & 0.67 & 0.67 \\
\hline 92 & 0 & 1 & 0.95 & -24 & -0.25 & 1 & 0.7 & 0.7 \\
\hline 93 & 0 & 0.9 & 0.95 & -23.9 & -0.34 & 0.9 & 0.63 & 0.63 \\
\hline 94 & 0 & 0.8 & 0.95 & -23.8 & -0.43 & 0.8 & 0.7 & 0.7 \\
\hline 95 & 0 & 0.7 & 0.95 & -23.7 & -0.52 & 0.7 & 0.67 & 0.67 \\
\hline 96 & 0 & 1.1 & 0.95 & -21.9 & -0.05 & 1.1 & 0.87 & 0.87 \\
\hline 97 & 0 & 1 & 0.95 & -22 & -0.15 & 1 & 0.7 & 0.7 \\
\hline 98 & 0 & 0.9 & 0.95 & -22.1 & -0.25 & 0.9 & 0.73 & 0.73 \\
\hline 99 & 0 & 0.8 & 0.95 & -22.2 & -0.35 & 0.8 & 0.6 & 0.6 \\
\hline 100 & 0 & 0.7 & 0.95 & -22.3 & -0.45 & 0.7 & 0.73 & 0.73 \\
\hline
\end{tabular}


SM 2. Study 2: Problems and Choice Rates

\begin{tabular}{|c|c|c|c|c|c|c|c|c|c|c|c|c|c|c|}
\hline \multirow{2}{*}{\multicolumn{2}{|c|}{ Problem number }} & \multicolumn{6}{|c|}{ Payoff distributions } & \multicolumn{4}{|c|}{ Valuations } & \multicolumn{3}{|c|}{ Choice Rates (of Option 2) } \\
\hline & & \multicolumn{3}{|c|}{ Option 1} & \multicolumn{3}{|c|}{ Option 2} & \multicolumn{2}{|c|}{ Expert EV } & \multicolumn{2}{|c|}{ Expert median } & \multicolumn{2}{|c|}{ CPC15 } & \multirow{2}{*}{$\begin{array}{l}\text { Here } \\
\text { fVal }\end{array}$} \\
\hline Here & $\mathrm{CPC} 15$ & $\mathrm{H} 1$ & $\mathrm{pH} 1$ & $\mathrm{~L} 1$ & $\mathrm{H} 2$ & $\mathrm{pH} 2$ & $\mathrm{~L} 2$ & EV1 & EV2 & Med1 & Med2 & fDesc & fExp & \\
\hline $\mathbf{1}$ & 1 & 3 & 1.00 & 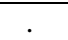 & 4 & 0.80 & 0 & 3.00 & 3.20 & 3 & 4.0 & 0.42 & 0.65 & 0.65 \\
\hline 2 & 2 & 3 & 0.25 & 0 & 4 & 0.20 & 0 & 0.75 & 0.80 & 0 & 0.0 & 0.61 & 0.62 & 0.43 \\
\hline 3 & 5 & -3 & 1.00 & . & 0 & 0.20 & -4 & -3.00 & -3.20 & -3 & -4.0 & 0.49 & 0.36 & 0.28 \\
\hline 4 & 6 & 0 & 0.75 & -3 & 0 & 0.80 & -4 & -0.75 & -0.80 & 0 & 0.0 & 0.38 & 0.41 & 0.43 \\
\hline 5 & 7 & -1 & 1.00 & . & 0 & 0.95 & -20 & -1.00 & -1.00 & -1 & 0.0 & 0.48 & 0.64 & 0.70 \\
\hline 6 & 8 & 1 & 1.00 & . & 20 & 0.05 & 0 & 1.00 & 1.00 & 1 & 0.0 & 0.39 & 0.29 & 0.23 \\
\hline 7 & 9 & 1 & 1.00 & . & 100 & 0.01 & 0 & 1.00 & 1.00 & 1 & 0.0 & 0.47 & 0.39 & 0.20 \\
\hline 8 & 10 & 2 & 1.00 & . & 101 & 0.01 & 1 & 2.00 & 2.00 & 2 & 1.0 & 0.55 & 0.42 & 0.28 \\
\hline 9 & 11 & 19 & 1.00 & . & 20 & 0.90 & -20 & 19.00 & 16.00 & 19 & 20.0 & 0.13 & 0.21 & 0.40 \\
\hline 10 & 15 & 7 & 1.00 & . & 50 & 0.50 & 1 & 7.00 & 25.50 & 7 & 25.5 & 0.78 & 0.85 & 0.70 \\
\hline 11 & 16 & 7 & 1.00 & . & 50 & 0.50 & -1 & 7.00 & 24.50 & 7 & 24.5 & 0.71 & 0.83 & 0.73 \\
\hline 12 & 17 & 30 & 1.00 & . & 50 & 0.50 & 1 & 30.00 & 25.50 & 30 & 25.5 & 0.24 & 0.29 & 0.23 \\
\hline 13 & 18 & 30 & 1.00 & . & 50 & 0.50 & -1 & 30.00 & 24.50 & 30 & 24.5 & 0.23 & 0.33 & 0.28 \\
\hline 14 & 19 & 9 & 1.00 & . & $9+a 8$ & 1.00 & . & 9.00 & 9.00 & 9 & 3.0 & 0.36 & 0.30 & 0.25 \\
\hline 15 & 20 & 9 & 1.00 & . & $9+a 8$ & 1.00 & . & 9.00 & 9.00 & 9 & 3.0 & 0.38 & 0.36 & 0.23 \\
\hline 16 & 26 & 16 & 1.00 & . & 50 & 0.40 & 1 & 16.00 & 20.60 & 16 & 1.0 & 0.50 & 0.55 & 0.28 \\
\hline 17 & 27 & 16 & 1.00 & . & 48-a3 & 0.40 & 1 & 16.00 & 19.80 & 16 & 1.0 & 0.50 & 0.57 & 0.50 \\
\hline 18 & 28 & 6 & 0.50 & 0 & 9 & 0.50 & 0 & 3.00 & 4.50 & 3 & 4.5 & 0.91 & 0.84 & 0.73 \\
\hline 19 & 29 & 2 & 1.00 & . & 3 & 1.00 & . & 2.00 & 3.00 & 2 & 3.0 & 0.97 & 1.00 & 0.70 \\
\hline 20 & 30 & 6 & 0.50 & 0 & 8 & 0.50 & 0 & 3.00 & 4.00 & 3 & 4.0 & 0.94 & 0.98 & 0.78 \\
\hline 21 & 32 & 24 & 0.75 & -4 & 82 & 0.25 & 3 & 17.00 & 22.75 & 24 & 3.0 & 0.68 & 0.69 & 0.33 \\
\hline 22 & 33 & -3 & 1.00 & . & 14 & 0.40 & -22 & -3.00 & -7.60 & -3 & -22.0 & 0.33 & 0.22 & 0.23 \\
\hline 23 & 34 & 7 & 1.00 & . & $27+s 3$ & 0.10 & 4 & 7.00 & 6.30 & 7 & 4.0 & 0.39 & 0.40 & 0.20 \\
\hline 24 & 35 & -5 & 1.00 & . & 47 & 0.01 & -15 & -5.00 & -14.38 & -5 & -15.0 & 0.18 & 0.05 & 0.25 \\
\hline 25 & 36 & 28 & 1.00 & . & $88+a 3$ & 0.60 & -46 & 28.00 & 34.40 & 28 & 86.0 & 0.39 & 0.57 & 0.65 \\
\hline 26 & 37 & 23 & 0.90 & 0 & 64 & 0.40 & -7 & 20.70 & 21.40 & 23 & -7.0 & 0.38 & 0.37 & 0.20 \\
\hline 27 & 38 & 24 & 1.00 & . & 34 & 0.05 & 28 & 24.00 & 28.30 & 24 & 28.0 & 0.91 & 1.00 & 0.68 \\
\hline 28 & 39 & 29 & 1.00 & . & $33+s 5$ & 0.80 & 6 & 29.00 & 27.60 & 29 & 33.0 & 0.50 & 0.66 & 0.43 \\
\hline 29 & 40 & 3 & 0.80 & -37 & 79 & 0.40 & -46 & -5.00 & 4.00 & 3 & -46.0 & 0.49 & 0.56 & 0.30 \\
\hline 30 & 41 & 29 & 1.00 & . & $44+s 5$ & 0.40 & 21 & 29.00 & 30.20 & 29 & 21.0 & 0.68 & 0.68 & 0.38 \\
\hline 31 & 43 & 14 & 1.00 & . & 12 & 0.90 & 9 & 14.00 & 11.70 & 14 & 12.0 & 0.13 & 0.00 & 0.28 \\
\hline 32 & 44 & 23 & 1.00 & . & 24 & 0.99 & -33 & 23.00 & 23.43 & 23 & 24.0 & 0.27 & 0.47 & 0.63 \\
\hline 33 & 46 & 37 & 0.01 & 9 & 30 & 0.60 & -37 & 9.28 & 3.20 & 9 & 30.0 & 0.20 & 0.30 & 0.58 \\
\hline 34 & 47 & 11 & 1.00 & . & 57-a6 & 0.20 & -5 & 11.00 & 7.40 & 11 & -5.0 & 0.21 & 0.15 & 0.28 \\
\hline 35 & 51 & 42 & 0.80 & -18 & 68 & 0.20 & 23 & 30.00 & 32.00 & 42 & 23.0 & 0.79 & 0.70 & 0.35 \\
\hline 36 & 52 & 46 & 0.20 & 0 & 46 & 0.25 & -2 & 9.20 & 10.00 & 0 & -2.00 & 0.36 & 0.22 & 0.35 \\
\hline 37 & 53 & 28 & 1.00 & . & 42 & 0.75 & -22 & 28.00 & 26.00 & 28 & 42.0 & 0.36 & 0.41 & 0.60 \\
\hline 38 & 54 & 18 & 1.00 & . & 64 & 0.50 & -33 & 18.00 & 15.50 & 18 & 15.5 & 0.32 & 0.29 & 0.40 \\
\hline 39 & 55 & 43 & 0.20 & 19 & $22+s 9$ & 0.25 & 17 & 23.80 & 18.25 & 19 & 17.0 & 0.20 & 0.07 & 0.35 \\
\hline 40 & 56 & -8 & 1.00 & . & -5 & 0.99 & -34 & -8.00 & -5.29 & -8 & -5.00 & 0.76 & 0.89 & 0.60 \\
\hline 41 & 57 & 49 & 0.50 & -3 & $33+s 9$ & 0.95 & 17 & 23.00 & 32.20 & 23 & 33.0 & 0.77 & 0.75 & 0.78 \\
\hline 42 & 58 & 85 & 0.40 & -7 & 40 & 0.25 & 24 & 29.80 & 28.00 & -7 & 24.0 & 0.60 & 0.56 & 0.73 \\
\hline 43 & 59 & 17 & 0.25 & 16 & 43 & 0.40 & 2 & 16.25 & 18.40 & 16 & 2.00 & 0.51 & 0.49 & 0.30 \\
\hline 44 & 60 & 51 & 0.10 & 21 & 38 & 0.60 & 1 & 24.00 & 23.20 & 21 & 38.0 & 0.37 & 0.30 & 0.70 \\
\hline 45 & 61 & 26 & 0.25 & 25 & $29+a 7$ & 0.05 & 24 & 25.25 & 24.25 & 25 & 24.0 & 0.67 & 0.56 & 0.23 \\
\hline 46 & 62 & 25 & 1.00 & . & 45 & 0.20 & 17 & 25.00 & 22.60 & 25 & 17.0 & 0.32 & 0.34 & 0.30 \\
\hline 47 & 63 & 17 & 1.00 & . & $60+s 5$ & 0.10 & 15 & 17.00 & 19.50 & 17 & 15.0 & 0.68 & 0.69 & 0.55 \\
\hline 48 & 65 & 12 & 0.40 & -16 & -5 & 1.00 & . & -4.80 & -5.00 & -16 & -5.0 & 0.33 & 0.45 & 0.75 \\
\hline 49 & 66 & 45 & 0.60 & 2 & 54-a5 & 0.10 & 20 & 27.80 & 23.40 & 45 & 20.0 & 0.43 & 0.43 & 0.40 \\
\hline 50 & 67 & 85 & 0.25 & 4 & 54 & 0.25 & 11 & 24.25 & 21.75 & 4 & 11.0 & 0.45 & 0.43 & 0.50 \\
\hline 51 & 68 & 12 & 1.00 & . & 102 & 0.20 & -14 & 12.00 & 9.20 & 12 & -14.0 & 0.39 & 0.31 & 0.25 \\
\hline 52 & 70 & 18 & 1.00 & . & 35 & 0.75 & -19 & 18.00 & 21.50 & 18 & 35.0 & 0.38 & 0.58 & 0.63 \\
\hline 53 & 71 & 13 & 0.60 & -20 & 76 & 0.20 & -26 & -0.20 & -5.60 & 13 & -26.0 & 0.38 & 0.28 & 0.18 \\
\hline 54 & 72 & -9 & 1.00 & . & 13 & 0.25 & -8 & -9.00 & -2.75 & -9 & -8.0 & 0.82 & 1.00 & 0.65 \\
\hline 55 & 73 & 2 & 1.00 & . & $51+\mathrm{s} 7$ & 0.05 & 0 & 2.00 & 2.55 & 2 & 0.00 & 0.37 & 0.41 & 0.40 \\
\hline 56 & 75 & 13 & 1.00 & . & 50 & 0.60 & -45 & 13.00 & 12.00 & 13 & 50.0 & 0.35 & 0.50 & 0.75 \\
\hline 57 & 77 & 1 & 1.00 & . & 38 & 0.40 & -9 & 1.00 & 9.80 & 1 & -9.0 & 0.65 & 0.63 & 0.40 \\
\hline
\end{tabular}




\begin{tabular}{|c|c|c|c|c|c|c|c|c|c|c|c|c|c|c|}
\hline 58 & 78 & 19 & 1.00 & . & 44 & 0.05 & 9 & 19.00 & 10.75 & 19 & 9.00 & 0.11 & 0.12 & 0.23 \\
\hline 59 & 79 & 32 & 0.01 & 19 & 65 & 0.01 & 9 & 19.13 & 9.56 & 19 & 9.00 & 0.14 & 0.02 & 0.20 \\
\hline 60 & 80 & 3 & 1.00 & . & 50 & 0.40 & -36 & 3.00 & -1.60 & 3 & -36.0 & 0.47 & 0.43 & 0.28 \\
\hline 61 & 83 & 9 & 1.00 & . & 64 & 0.01 & 9 & 9.00 & 9.55 & 9 & 9.00 & 0.87 & 0.99 & 0.58 \\
\hline 62 & 84 & 27 & 1.00 & . & 22 & 0.99 & -7 & 27.00 & 21.71 & 27 & 22.0 & 0.08 & 0.00 & 0.23 \\
\hline 63 & 85 & 20 & 1.00 & . & 70 & 0.25 & 6 & 20.00 & 22.00 & 20 & 6.00 & 0.43 & 0.44 & 0.15 \\
\hline 64 & 87 & -2 & 1.00 & . & $4+s 7$ & 0.99 & -34 & -2.00 & 3.62 & -2 & 4.00 & 0.81 & 0.98 & 0.78 \\
\hline 65 & 89 & 17 & 1.00 & . & 44 & 0.10 & 17 & 17.00 & 19.70 & 17 & 17.0 & 0.88 & 1.00 & 0.70 \\
\hline 66 & 90 & 10 & 1.00 & . & 31 & 0.75 & -49 & 10.00 & 11.00 & 10 & 31.0 & 0.42 & 0.55 & 0.68 \\
\hline 67 & 91 & 7 & 1.00 & . & 16 & 0.10 & 10 & 7.00 & 10.60 & 7 & 10.0 & 0.92 & 1.00 & 0.70 \\
\hline 68 & 92 & 8 & 0.80 & -37 & 102 & 0.20 & -29 & -1.00 & -2.80 & 8 & -29.0 & 0.39 & 0.32 & 0.25 \\
\hline 69 & 94 & 7 & 1.00 & . & 6 & 0.75 & 1 & 7.00 & 4.75 & 7 & 6.00 & 0.10 & 0.02 & 0.25 \\
\hline 70 & 95 & -3 & 0.05 & -9 & $42-a 7$ & 0.40 & -24 & -8.70 & 2.40 & -9 & -24.0 & 0.72 & 0.57 & 0.43 \\
\hline 71 & 96 & 35 & 0.50 & -47 & -10 & 0.75 & -15 & -6.00 & -11.25 & -6 & -10.0 & 0.30 & 0.31 & 0.23 \\
\hline 72 & 97 & 10 & 1.00 & . & 45 & 0.20 & -5 & 10.00 & 5.00 & 10 & -5.0 & 0.22 & 0.21 & 0.20 \\
\hline 73 & 98 & 94 & 0.50 & -40 & $36+s 7$ & 0.75 & -21 & 27.00 & 21.75 & 27 & 35.0 & 0.51 & 0.45 & 0.60 \\
\hline 74 & 99 & 22 & 1.00 & . & $44+\mathrm{s} 5$ & 0.40 & 15 & 22.00 & 26.60 & 22 & 15.0 & 0.65 & 0.71 & 0.45 \\
\hline 75 & 100 & 18 & 0.60 & -29 & -1 & 1.00 & . & -0.80 & -1.00 & 18 & -1.0 & 0.54 & 0.53 & 0.33 \\
\hline 76 & 101 & 28 & 1.00 & . & $73+s 3$ & 0.05 & 27 & 28.00 & 29.30 & 28 & 27.0 & 0.83 & 0.76 & 0.40 \\
\hline 77 & 103 & 27 & 0.80 & -4 & $77+a 6$ & 0.10 & 22 & 20.80 & 27.50 & 27 & 22.0 & 0.83 & 0.77 & 0.53 \\
\hline 78 & 104 & -6 & 1.00 & . & 3 & 0.99 & -27 & -6.00 & 2.70 & -6 & 3.0 & 0.85 & 0.98 & 0.78 \\
\hline 79 & 105 & 30 & 1.00 & . & 90 & 0.01 & 36 & 30.00 & 36.54 & 30 & 36.0 & 0.90 & 1.00 & 0.68 \\
\hline 80 & 106 & 2 & 1.00 & . & $34+s 5$ & 0.05 & -5 & 2.00 & -3.05 & 2 & -5.0 & 0.20 & 0.12 & 0.23 \\
\hline 81 & 107 & 25 & 1.00 & . & $65+\mathrm{s} 5$ & 0.25 & 9 & 25.00 & 23.00 & 25 & 9.0 & 0.39 & 0.32 & 0.28 \\
\hline 82 & 108 & 16 & 1.00 & . & 91 & 0.20 & -11 & 16.00 & 9.40 & 16 & -11.0 & 0.27 & 0.18 & 0.28 \\
\hline 83 & 109 & 11 & 1.00 & . & 26 & 0.50 & -9 & 11.00 & 8.50 & 11 & 8.5 & 0.33 & 0.40 & 0.25 \\
\hline 84 & 110 & 12 & 1.00 & . & $29+s 2$ & 0.80 & -35 & 12.00 & 16.20 & 12 & 28.0 & 0.56 & 0.77 & 0.60 \\
\hline 85 & 111 & 28 & 1.00 & . & 47 & 0.60 & -13 & 28.00 & 23.00 & 28 & 47.0 & 0.25 & 0.39 & 0.50 \\
\hline 86 & 112 & -7 & 1.00 & . & $28+s 7$ & 0.20 & -18 & -7.00 & -8.80 & -7 & -18.0 & 0.51 & 0.26 & 0.20 \\
\hline 87 & 113 & 9 & 0.95 & $\dot{0}$ & $37+a 6$ & 0.25 & -3 & 8.55 & 7.00 & 9 & -3.0 & 0.35 & 0.37 & 0.20 \\
\hline 88 & 114 & 72 & 0.01 & -2 & 112 & 0.25 & -33 & -1.26 & 3.25 & -2 & -33.0 & 0.44 & 0.32 & 0.38 \\
\hline 89 & 115 & 50 & 0.40 & 5 & $20+s 7$ & 0.80 & -17 & 23.00 & 12.60 & 5 & 20.0 & 0.17 & 0.20 & 0.60 \\
\hline 90 & 116 & 2 & 1.00 & . & $45+s 5$ & 0.05 & 3 & 2.00 & 5.10 & 2 & 3.0 & 0.95 & 1.00 & 0.55 \\
\hline 91 & 117 & -6 & 1.00 & . & 7 & 0.50 & -30 & -6.00 & -11.50 & -6 & -11.5 & 0.33 & 0.34 & 0.18 \\
\hline 92 & 118 & 26 & 1.00 & . & 46-a6 & 0.50 & 10 & 26.00 & 28.00 & 26 & 10.0 & 0.47 & 0.57 & 0.23 \\
\hline 93 & 119 & 19 & 0.40 & 12 & $100+s 2$ & 0.25 & -12 & 14.80 & 16.00 & 12 & -12.0 & 0.33 & 0.35 & 0.15 \\
\hline 94 & 120 & -9 & 0.95 & -26 & -1 & 0.10 & -11 & -9.85 & -10.00 & -9 & -11.0 & 0.57 & 0.42 & 0.23 \\
\hline 95 & 121 & -8 & 1.00 & . & $21+\mathrm{s} 3$ & 0.01 & 0 & -8.00 & 0.21 & -8 & 0.0 & 0.79 & 0.99 & 0.73 \\
\hline 96 & 122 & 68 & 0.05 & -14 & -11 & 0.90 & -36 & -9.90 & -13.50 & -14 & -11.0 & 0.36 & 0.40 & 0.48 \\
\hline 97 & 123 & 28 & 0.75 & -13 & 57 & 0.10 & 16 & 17.75 & 20.10 & 28 & 16.0 & 0.74 & 0.63 & 0.23 \\
\hline 98 & 124 & 15 & 0.95 & 7 & 42 & 0.01 & 19 & 14.60 & 19.23 & 15 & 19.0 & 0.85 & 0.98 & 0.85 \\
\hline 99 & 125 & 28 & 1.00 & . & 41 & 0.40 & 12 & 28.00 & 23.60 & 28 & 12.0 & 0.29 & 0.36 & 0.23 \\
\hline 100 & 126 & -8 & 1.00 & . & $80+s 7$ & 0.20 & -18 & -8.00 & 1.60 & -8 & -18.0 & 0.53 & 0.52 & 0.53 \\
\hline 101 & 128 & -3 & 1.00 & . & 32 & 0.40 & -16 & -3.00 & 3.20 & -3 & -16.0 & 0.64 & 0.56 & 0.38 \\
\hline 102 & 130 & 72 & 0.40 & -41 & 16 & 0.01 & 1 & 4.20 & 1.15 & -41 & 1.00 & 0.61 & 0.54 & 0.78 \\
\hline 103 & 131 & 18 & 1.00 & . & 45 & 0.01 & 11 & 18.00 & 11.34 & 18 & 11.0 & 0.19 & 0.06 & 0.28 \\
\hline 104 & 132 & 11 & 1.00 & . & $20+s 7$ & 0.99 & 4 & 11.00 & 19.84 & 11 & 20.0 & 0.81 & 0.98 & 0.75 \\
\hline 105 & 133 & 3 & 1.00 & . & $8+\mathrm{s} 9$ & 0.99 & -17 & 3.00 & 7.75 & 3 & 8.0 & 0.71 & 0.94 & 0.70 \\
\hline 106 & 134 & 27 & 0.05 & 24 & $31+s 3$ & 0.50 & 10 & 24.15 & 20.50 & 24 & 20.0 & 0.34 & 0.37 & 0.25 \\
\hline 107 & 135 & 6 & 1.00 & . & 8 & 0.50 & -1 & 6.00 & 3.50 & 6 & 3.5 & 0.25 & 0.29 & 0.23 \\
\hline 108 & 136 & 4 & 1.00 & . & 25 & 0.01 & -5 & 4.00 & -4.70 & 4 & -5.0 & 0.16 & 0.05 & 0.23 \\
\hline 109 & 138 & 23 & 1.00 & . & 21 & 0.80 & 16 & 23.00 & 20.00 & 23 & 21.0 & 0.13 & 0.02 & 0.25 \\
\hline 110 & 139 & 14 & 1.00 & . & $35+s 7$ & 0.60 & -9 & 14.00 & 17.40 & 14 & 34.0 & 0.48 & 0.65 & 0.70 \\
\hline 111 & 140 & -2 & 1.00 & & 9 & 0.25 & 8 & -2.00 & 8.25 & -2 & 8.0 & 0.91 & 0.98 & 0.78 \\
\hline 112 & 141 & 28 & 0.80 & -26 & 22 & 0.75 & 2 & 17.20 & 17.00 & 28 & 22.0 & 0.77 & 0.62 & 0.33 \\
\hline 113 & 142 & 23 & 1.00 & . & 29 & 0.80 & -8 & 23.00 & 21.60 & 23 & 29.0 & 0.30 & 0.54 & 0.73 \\
\hline 114 & 143 & 67 & 0.50 & -39 & 93 & 0.25 & -15 & 14.00 & 12.00 & 14 & -15.0 & 0.53 & 0.63 & 0.18 \\
\hline 115 & 144 & 16 & 0.80 & 12 & $15+\mathrm{s} 9$ & 1.00 & . & 15.20 & 15.00 & 16 & 15.0 & 0.42 & 0.42 & 0.40 \\
\hline 116 & 145 & 17 & 0.50 & -27 & $3+\mathrm{s} 7$ & 0.75 & -35 & -5.00 & -6.50 & -5 & 2.0 & 0.42 & 0.34 & 0.60 \\
\hline 117 & 146 & 45 & 0.20 & 3 & $75+\mathrm{s} 5$ & 0.05 & 13 & 11.40 & 16.10 & 3 & 13.0 & 0.79 & 0.84 & 0.80 \\
\hline 118 & 147 & 29 & 1.00 & . & $36+s 7$ & 0.10 & 32 & 29.00 & 32.40 & 29 & 32.0 & 0.88 & 0.97 & 0.60 \\
\hline
\end{tabular}




$\begin{array}{lllllllllllllll}\mathbf{1 1 9} & 149 & 12 & 1.00 & . & 31+\mathrm{s} 3 & 0.10 & 12 & 12.00 & 13.90 & 12 & 12.0 & 0.86 & 0.94 & 0.65 \\ \mathbf{1 2 0} & 150 & 16 & 1.00 & . & 24-\mathrm{a} 3 & 0.05 & 12 & 16.00 & 12.60 & 16 & 12.0 & 0.35 & 0.17 & 0.23\end{array}$

Notes. The left-hand side presents the 120 problems (from CPC15) used in Study 2. Option 1 yields H1 with probability $\mathrm{pH} 1$, and $\mathrm{L} 1$ otherwise. Option 2 yields $\mathrm{H} 2$ with probability $\mathrm{pH} 2$, and $\mathrm{L} 2$ otherwise. In some of the problems, $\mathrm{H} 2$ is a lottery that provides a mean of $\mathrm{H} 2$ plus additional terms with a mean of 0 . The distribution of the additional terms is described below (a3,a5, e.t.c.). EV1 (EV2) and Med1 (Med2) present the expected values and medians of Option 1 (Option 2). The right-hand side presents the observed choice rates of Option 2 in CPC15 and the current study. Column fDesc (from description) presents the first five trials that were made from description. Column fExp (from experience) shows the choice rates in the last five trials after 15 to 19 trials with experience (feedback). Column fVal (from valuations) shows the choice rates in Study 2 here.

a3: a draw from $(-2,0.5 ; 0,0.25 ; 4)$

a5: a draw from $(-4,0.5 ;-2,0.25 ; 2,0.125 ; 10,0.00625 ; 26)$

a6: a draw from $(-5,0.5 ;-3,0.25 ; 1,0.125 ; 9,0.0625 ; 25,0.03125 ; 57)$

a7: a draw from $(-6,0.5 ;-4,0.25 ; 0,0.125 ; 8,0.0625 ; 24,0.03125 ; 56,0.03125 ; 120)$

a8: a draw from $(-7, .5 ;-5,0.25 ;-1,0.125 ;+7, .0625 ; 23,0.03125 ; 55,0.01563 ; 119,0.0078 ; 247)$

s2: a draw from $(-1,0.5 ; 1)$

s3: a draw from $(-1,0.25 ; 0,0.5 ; 1)$

s5: a draw from $(-2,0.0625 ;-1,0.25 ; 0,0.375 ; 1,0.25 ; 2)$

s7: a draw from $(-3,0.0156 ;-2 ; 0.09375 ;-1,0.23438 ; 0,0.31250 ; 1,0.23438 ; 2,0.09375 ; 3)$

s9: a draw from $(-4,0.0039 ;-3,0.03125 ;-2,0.10938 ;-1,0.21875 ; 0,0.27344 ; 1,0.21875 ; 2,0.10938 ; 3,0.031,4)$ 
SM 3. Study 3: Problems and Choice Rates

All the problems involved a choice between a safe prospect that provides " $\mathrm{S}+\mathrm{C}$ " plus error, and a riskier prospect that provided " $\left(\mathrm{S}, 0.9 ; \mathrm{V}_{08}, 0.08 ; \mathrm{V}_{02}, 0.02\right)+\mathrm{C}$ " plus error. Thus, in $90 \%$ of the trials, the basic (error-free) payoff from the two prospects was identical (equaled $\mathrm{S}+\mathrm{C}$ ). In these trials, the error term determined the proportion of trials in which each expert is more likely to lead to the best ex-post choice (minimizes the probability of regret). The error term $\mathrm{u}_{10}$ was drawn from $\mathrm{U}[-5,+5]$, and the error term $\mathrm{u}_{90}$ equaled $\mathrm{u}_{10}+1$ if $\mathrm{u}_{10}<4$, and $\mathrm{u}_{10}-9$ otherwise. Thus, while the distribution of the error terms was identical, $\mathrm{u}_{90}$ was higher than $\mathrm{u}_{10}$ in $90 \%$ of the trials. In Condition "Median wins more," only the error of the option with higher median $\left(\varepsilon_{\mathrm{M}}\right)$ was $\mathrm{u}_{90}$, and in Condition "EV wins more," only the error of the option with higher $\mathrm{EV}\left(\varepsilon_{\mathrm{E}}\right)$ was $\mathrm{u}_{90}$.

\begin{tabular}{|c|c|c|c|c|c|c|c|c|c|c|}
\hline \multirow[b]{3}{*}{ Problem } & \multirow[b]{3}{*}{$\mathrm{C}$} & \multirow[b]{3}{*}{$\mathrm{S}$} & \multirow[b]{3}{*}{$\mathrm{V}_{08}$} & \multirow[b]{3}{*}{$\mathrm{V}_{02}$} & \multicolumn{4}{|c|}{ Valuations } & \multicolumn{2}{|c|}{ Risk choice rate } \\
\hline & & & & & \multicolumn{2}{|c|}{ Expert EV } & \multicolumn{2}{|c|}{ Expert Median } & \multirow{2}{*}{$\begin{array}{c}\text { Median } \\
\text { wins more }\end{array}$} & \multirow{2}{*}{$\begin{array}{c}\text { EV wins } \\
\text { more }\end{array}$} \\
\hline & & & & & Safe & Risk & Safe & Risk & & \\
\hline 1 & 2.26 & 2 & 10 & -100 & 4.26 & 2.86 & 4.26 & 4.59 & 0.55 & 0.40 \\
\hline 2 & 2.29 & 1 & 10 & -100 & 3.29 & 1.99 & 3.29 & 3.62 & 0.57 & 0.35 \\
\hline 3 & 2.3 & 0 & 10 & -100 & 2.30 & 1.10 & 2.30 & 2.63 & 0.59 & 0.36 \\
\hline 4 & 2.33 & -1 & 10 & -100 & 1.33 & 0.23 & 1.33 & 1.66 & 0.58 & 0.53 \\
\hline 5 & 2.85 & -2 & 10 & -100 & 0.85 & -0.15 & 0.85 & 1.18 & 0.50 & 0.28 \\
\hline 6 & 3 & 1 & 10 & -100 & 4.00 & 2.70 & 4.00 & 4.33 & 0.53 & 0.37 \\
\hline 7 & 3.24 & 0 & 10 & -100 & 3.24 & 2.04 & 3.24 & 3.57 & 0.58 & 0.40 \\
\hline 8 & 3.36 & 2 & 10 & -100 & 5.36 & 3.96 & 5.36 & 5.69 & 0.55 & 0.51 \\
\hline 9 & 3.73 & -1 & 10 & -100 & 2.73 & 1.63 & 2.73 & 3.06 & 0.55 & 0.40 \\
\hline 10 & 3.96 & -2 & 10 & -100 & 1.96 & 0.96 & 1.96 & 2.29 & 0.53 & 0.40 \\
\hline 11 & 4.26 & 2 & 10 & -100 & 6.26 & 4.86 & 6.26 & 6.59 & 0.60 & 0.30 \\
\hline 12 & 4.42 & 0 & 10 & -100 & 4.42 & 3.22 & 4.42 & 4.75 & 0.56 & 0.41 \\
\hline 13 & 4.57 & -1 & 10 & -100 & 3.57 & 2.47 & 3.57 & 3.9 & 0.56 & 0.45 \\
\hline 14 & 4.8 & 1 & 10 & -100 & 5.8 & 4.5 & 5.8 & 6.13 & 0.59 & 0.48 \\
\hline 15 & 4.83 & -2 & 10 & -100 & 2.83 & 1.83 & 2.83 & 3.16 & 0.56 & 0.41 \\
\hline 16 & 5.13 & 2 & 10 & -100 & 7.13 & 5.73 & 7.13 & 7.46 & 0.63 & 0.34 \\
\hline 17 & 5.17 & -1 & 10 & -100 & 4.17 & 3.07 & 4.17 & 4.5 & 0.52 & 0.36 \\
\hline 18 & 5.81 & 0 & 10 & -100 & 5.81 & 4.61 & 5.81 & 6.14 & 0.55 & 0.38 \\
\hline 19 & 5.87 & -2 & 10 & -100 & 3.87 & 2.87 & 3.87 & 4.2 & 0.60 & 0.42 \\
\hline 20 & 5.93 & 1 & 10 & -100 & 6.93 & 5.63 & 6.93 & 7.26 & 0.50 & 0.48 \\
\hline 21 & 6.24 & -1 & 10 & -100 & 5.24 & 4.14 & 5.24 & 5.57 & 0.54 & 0.39 \\
\hline 22 & 6.26 & -2 & 10 & -100 & 4.26 & 3.26 & 4.26 & 4.59 & 0.58 & 0.36 \\
\hline 23 & 6.46 & 1 & 10 & -100 & 7.46 & 6.16 & 7.46 & 7.79 & 0.51 & 0.37 \\
\hline 24 & 6.49 & 2 & 10 & -100 & 8.49 & 7.09 & 8.49 & 8.82 & 0.60 & 0.39 \\
\hline 25 & 6.61 & 0 & 10 & -100 & 6.61 & 5.41 & 6.61 & 6.94 & 0.60 & 0.46 \\
\hline 26 & 7.08 & -1 & 10 & -100 & 6.08 & 4.98 & 6.08 & 6.41 & 0.53 & 0.43 \\
\hline 27 & 7.4 & 2 & 10 & -100 & 9.4 & 8.00 & 9.4 & 9.73 & 0.52 & 0.38 \\
\hline 28 & 7.41 & 0 & 10 & -100 & 7.41 & 6.21 & 7.41 & 7.74 & 0.60 & 0.49 \\
\hline 29 & 7.45 & -2 & 10 & -100 & 5.45 & 4.45 & 5.45 & 5.78 & 0.58 & 0.41 \\
\hline 30 & 7.56 & 1 & 10 & -100 & 8.56 & 7.26 & 8.56 & 8.89 & 0.53 & 0.39 \\
\hline
\end{tabular}




\begin{tabular}{|c|c|c|c|c|c|c|c|c|c|c|}
\hline 31 & 8.06 & 1 & 10 & -100 & 9.06 & 7.76 & 9.06 & 9.39 & 0.54 & 0.45 \\
\hline 32 & 8.18 & -2 & 10 & -100 & 6.18 & 5.18 & 6.18 & 6.51 & 0.55 & 0.30 \\
\hline 33 & 8.36 & 0 & 10 & -100 & 8.36 & 7.16 & 8.36 & 8.69 & 0.52 & 0.46 \\
\hline 34 & 8.9 & -1 & 10 & -100 & 7.90 & 6.80 & 7.90 & 8.23 & 0.51 & 0.41 \\
\hline 35 & 8.94 & 2 & 10 & -100 & 10.94 & 9.54 & 10.94 & 11.27 & 0.52 & 0.42 \\
\hline 36 & 9.06 & 2 & 10 & -100 & 11.06 & 9.66 & 11.06 & 11.39 & 0.52 & 0.32 \\
\hline 37 & 9.41 & -2 & 10 & -100 & 7.41 & 6.41 & 7.41 & 7.74 & 0.57 & 0.40 \\
\hline 38 & 9.42 & -1 & 10 & -100 & 8.42 & 7.32 & 8.42 & 8.75 & 0.48 & 0.35 \\
\hline 39 & 9.46 & 1 & 10 & -100 & 10.46 & 9.16 & 10.46 & 10.79 & 0.48 & 0.41 \\
\hline 40 & 9.52 & 0 & 10 & -100 & 9.52 & 8.32 & 9.52 & 9.85 & 0.65 & 0.40 \\
\hline 41 & 10.07 & 0 & 10 & -100 & 10.07 & 8.87 & 10.07 & 10.4 & 0.56 & 0.32 \\
\hline 42 & 10.17 & -2 & 10 & -100 & 8.17 & 7.17 & 8.17 & 8.5 & 0.52 & 0.38 \\
\hline 43 & 10.56 & 1 & 10 & -100 & 11.56 & 10.26 & 11.56 & 11.89 & 0.50 & 0.41 \\
\hline 44 & 10.88 & -1 & 10 & -100 & 9.88 & 8.78 & 9.88 & 10.21 & 0.50 & 0.48 \\
\hline 45 & 10.96 & 2 & 10 & -100 & 12.96 & 11.56 & 12.96 & 13.29 & 0.62 & 0.49 \\
\hline 46 & 11.18 & 2 & 10 & -100 & 13.18 & 11.78 & 13.18 & 13.51 & 0.51 & 0.35 \\
\hline 47 & 11.44 & -1 & 10 & -100 & 10.44 & 9.34 & 10.44 & 10.77 & 0.55 & 0.37 \\
\hline 48 & 11.61 & 0 & 10 & -100 & 11.61 & 10.41 & 11.61 & 11.94 & 0.63 & 0.41 \\
\hline 49 & 11.76 & 1 & 10 & -100 & 12.76 & 11.46 & 12.76 & 13.09 & 0.56 & 0.42 \\
\hline 50 & 11.81 & -2 & 10 & -100 & 9.81 & 8.81 & 9.81 & 10.14 & 0.55 & 0.40 \\
\hline 51 & 2.26 & 2 & -10 & 100 & 4.26 & 5.26 & 4.26 & 3.93 & 0.42 & 0.48 \\
\hline 52 & 2.29 & 1 & -10 & 100 & 3.29 & 4.39 & 3.29 & 2.96 & 0.45 & 0.68 \\
\hline 53 & 2.3 & 0 & -10 & 100 & 2.30 & 3.50 & 2.30 & 1.97 & 0.42 & 0.63 \\
\hline 54 & 2.33 & -1 & -10 & 100 & 1.33 & 2.63 & 1.33 & 1.00 & 0.41 & 0.61 \\
\hline 55 & 2.85 & -2 & -10 & 100 & 0.85 & 2.25 & 0.85 & 0.52 & 0.50 & 0.59 \\
\hline 56 & 3 & 1 & -10 & 100 & 4.00 & 5.10 & 4.00 & 3.67 & 0.44 & 0.50 \\
\hline 57 & 3.24 & 0 & -10 & 100 & 3.24 & 4.44 & 3.24 & 2.91 & 0.49 & 0.62 \\
\hline 58 & 3.36 & 2 & -10 & 100 & 5.36 & 6.36 & 5.36 & 5.03 & 0.41 & 0.64 \\
\hline 59 & 3.73 & -1 & -10 & 100 & 2.73 & 4.03 & 2.73 & 2.40 & 0.47 & 0.56 \\
\hline 60 & 3.96 & -2 & -10 & 100 & 1.96 & 3.36 & 1.96 & 1.63 & 0.37 & 0.62 \\
\hline 61 & 4.26 & 2 & -10 & 100 & 6.26 & 7.26 & 6.26 & 5.93 & 0.43 & 0.62 \\
\hline 62 & 4.42 & 0 & -10 & 100 & 4.42 & 5.62 & 4.42 & 4.09 & 0.47 & 0.66 \\
\hline 63 & 4.57 & -1 & -10 & 100 & 3.57 & 4.87 & 3.57 & 3.24 & 0.41 & 0.54 \\
\hline 64 & 4.8 & 1 & -10 & 100 & 5.80 & 6.90 & 5.8 & 5.47 & 0.40 & 0.56 \\
\hline 65 & 4.83 & -2 & -10 & 100 & 2.83 & 4.23 & 2.83 & 2.50 & 0.45 & 0.61 \\
\hline 66 & 5.13 & 2 & -10 & 100 & 7.13 & 8.13 & 7.13 & 6.80 & 0.44 & 0.60 \\
\hline 67 & 5.17 & -1 & -10 & 100 & 4.17 & 5.47 & 4.17 & 3.84 & 0.50 & 0.66 \\
\hline 68 & 5.81 & 0 & -10 & 100 & 5.81 & 7.01 & 5.81 & 5.48 & 0.52 & 0.55 \\
\hline 69 & 5.87 & -2 & -10 & 100 & 3.87 & 5.27 & 3.87 & 3.54 & 0.55 & 0.62 \\
\hline 70 & 5.93 & 1 & -10 & 100 & 6.93 & 8.03 & 6.93 & 6.60 & 0.44 & 0.52 \\
\hline 71 & 6.24 & -1 & -10 & 100 & 5.24 & 6.54 & 5.24 & 4.91 & 0.41 & 0.65 \\
\hline 72 & 6.26 & -2 & -10 & 100 & 4.26 & 5.66 & 4.26 & 3.93 & 0.51 & 0.50 \\
\hline 73 & 6.46 & 1 & -10 & 100 & 7.46 & 8.56 & 7.46 & 7.13 & 0.42 & 0.59 \\
\hline
\end{tabular}




$\begin{array}{lcccccccccc}74 & 6.49 & 2 & -10 & 100 & 8.49 & 9.49 & 8.49 & 8.16 & 0.47 & 0.57 \\ 75 & 6.61 & 0 & -10 & 100 & 6.61 & 7.81 & 6.61 & 6.28 & 0.52 & 0.62 \\ 76 & 7.08 & -1 & -10 & 100 & 6.08 & 7.38 & 6.08 & 5.75 & 0.50 & 0.55 \\ 77 & 7.4 & 2 & -10 & 100 & 9.4 & 10.4 & 9.4 & 9.07 & 0.54 & 0.67 \\ 78 & 7.41 & 0 & -10 & 100 & 7.41 & 8.61 & 7.41 & 7.08 & 0.48 & 0.62 \\ 79 & 7.45 & -2 & -10 & 100 & 5.45 & 6.85 & 5.45 & 5.12 & 0.44 & 0.61 \\ 80 & 7.56 & 1 & -10 & 100 & 8.56 & 9.66 & 8.56 & 8.23 & 0.51 & 0.60 \\ 81 & 8.06 & 1 & -10 & 100 & 9.06 & 10.16 & 9.06 & 8.73 & 0.45 & 0.53 \\ 82 & 8.18 & -2 & -10 & 100 & 6.18 & 7.58 & 6.18 & 5.85 & 0.45 & 0.60 \\ 83 & 8.36 & 0 & -10 & 100 & 8.36 & 9.56 & 8.36 & 8.03 & 0.36 & 0.59 \\ 84 & 8.9 & -1 & -10 & 100 & 7.9 & 9.2 & 7.9 & 7.57 & 0.46 & 0.58 \\ 85 & 8.94 & 2 & -10 & 100 & 10.94 & 11.94 & 10.94 & 10.61 & 0.45 & 0.58 \\ 86 & 9.06 & 2 & -10 & 100 & 11.06 & 12.06 & 11.06 & 10.73 & 0.44 & 0.60 \\ 87 & 9.41 & -2 & -10 & 100 & 7.41 & 8.81 & 7.41 & 7.08 & 0.38 & 0.60 \\ 88 & 9.42 & -1 & -10 & 100 & 8.42 & 9.72 & 8.42 & 8.09 & 0.51 & 0.67 \\ 89 & 9.46 & 1 & -10 & 100 & 10.46 & 11.56 & 10.46 & 10.13 & 0.49 & 0.64 \\ 90 & 9.52 & 0 & -10 & 100 & 9.52 & 10.72 & 9.52 & 9.19 & 0.45 & 0.65 \\ 91 & 10.07 & 0 & -10 & 100 & 10.07 & 11.27 & 10.07 & 9.74 & 0.43 & 0.62 \\ 92 & 10.17 & -2 & -10 & 100 & 8.17 & 9.57 & 8.17 & 7.84 & 0.46 & 0.54 \\ 93 & 10.56 & 1 & -10 & 100 & 11.56 & 12.66 & 11.56 & 11.23 & 0.42 & 0.57 \\ 94 & 10.88 & -1 & -10 & 100 & 9.88 & 11.18 & 9.88 & 9.55 & 0.51 & 0.60 \\ 95 & 10.96 & 2 & -10 & 100 & 12.96 & 13.96 & 12.96 & 12.63 & 0.48 & 0.64 \\ 96 & 11.18 & 2 & -10 & 100 & 13.18 & 14.18 & 13.18 & 12.85 & 0.53 & 0.58 \\ 97 & 11.44 & -1 & -10 & 100 & 10.44 & 11.74 & 10.44 & 10.11 & 0.51 & 0.58 \\ 98 & 11.61 & 0 & -10 & 100 & 11.61 & 12.81 & 11.61 & 11.28 & 0.48 & 0.58 \\ 99 & 11.76 & 1 & -10 & 100 & 12.76 & 13.86 & 12.76 & 12.43 & 0.42 & 0.64 \\ 100 & 11.81 & -2 & -10 & 100 & 9.81 & 11.21 & 9.81 & 9.48 & 0.43 & 0.64\end{array}$


SM 4. Study 4: Problems and Choice Rates

\begin{tabular}{|c|c|c|c|c|c|c|c|c|c|c|c|}
\hline \multirow[b]{2}{*}{ Problem } & \multirow[b]{2}{*}{ Safe } & \multirow[b]{2}{*}{$\begin{array}{c}\text { Risk } \\
\mathrm{H}\end{array}$} & \multirow[b]{2}{*}{$\begin{array}{c}\mathrm{P}(\text { Risk } \\
\mathrm{H})\end{array}$} & \multirow[b]{2}{*}{$\begin{array}{c}\text { Risk } \\
\text { L }\end{array}$} & \multicolumn{3}{|c|}{$\begin{array}{c}\text { Experts' valuations of the risky } \\
\text { prospect }\end{array}$} & \multicolumn{4}{|c|}{ Maximization rates } \\
\hline & & & & & EV & Exaggerated & Median & Calibrated1 & Biased1 & Calibrated 100 & Biased 100 \\
\hline 1 & 0 & 24.1 & 0.05 & -1.1 & 0.160 & 2.1 & -1.1 & 0.26 & 0.65 & 0.65 & 0.97 \\
\hline 2 & 0 & 24.0 & 0.05 & -1.0 & 0.250 & 2.0 & -1.0 & 0.29 & 0.63 & 0.63 & 0.93 \\
\hline 3 & 0 & 23.9 & 0.05 & -0.9 & 0.340 & 1.9 & -0.9 & 0.29 & 0.78 & 0.78 & 0.97 \\
\hline 4 & 0 & 23.8 & 0.05 & -0.8 & 0.430 & 1.8 & -0.8 & 0.26 & 0.75 & 0.75 & 0.90 \\
\hline 5 & 0 & 23.7 & 0.05 & -0.7 & 0.520 & 1.7 & -0.7 & 0.45 & 0.75 & 0.75 & 0.97 \\
\hline 6 & 0 & 21.9 & 0.05 & -1.1 & 0.050 & 2.1 & -1.1 & 0.29 & 0.63 & 0.63 & 0.83 \\
\hline 7 & 0 & 22.0 & 0.05 & -1.0 & 0.150 & 2.0 & -1.0 & 0.23 & 0.73 & 0.73 & 0.93 \\
\hline 8 & 0 & 22.1 & 0.05 & -0.9 & 0.250 & 1.9 & -0.9 & 0.29 & 0.76 & 0.76 & 1.00 \\
\hline 9 & 0 & 22.2 & 0.05 & -0.8 & 0.350 & 1.8 & -0.8 & 0.35 & 0.69 & 0.69 & 0.93 \\
\hline 10 & 0 & 22.3 & 0.05 & -0.7 & 0.450 & 1.7 & -0.7 & 0.35 & 0.75 & 0.75 & 1.00 \\
\hline 11 & 0 & 17.1 & 0.07 & -1.1 & 0.174 & 2.1 & -1.1 & 0.29 & 0.73 & 0.73 & 0.90 \\
\hline 12 & 0 & 17.0 & 0.07 & -1.0 & 0.260 & 2.0 & -1.0 & 0.16 & 0.63 & 0.63 & 0.97 \\
\hline 13 & 0 & 16.9 & 0.07 & -0.9 & 0.346 & 1.9 & -0.9 & 0.29 & 0.63 & 0.63 & 0.90 \\
\hline 14 & 0 & 16.8 & 0.07 & -0.8 & 0.432 & 1.8 & -0.8 & 0.35 & 0.71 & 0.71 & 1.00 \\
\hline 15 & 0 & 16.7 & 0.07 & -0.7 & 0.518 & 1.7 & -0.7 & 0.39 & 0.69 & 0.69 & 0.90 \\
\hline 16 & 0 & 14.9 & 0.07 & -1.1 & 0.020 & 2.1 & -1.1 & 0.26 & 0.55 & 0.55 & 0.93 \\
\hline 17 & 0 & 15.0 & 0.07 & -1.0 & 0.120 & 2.0 & -1.0 & 0.19 & 0.63 & 0.63 & 0.90 \\
\hline 18 & 0 & 15.1 & 0.07 & -0.9 & 0.220 & 1.9 & -0.9 & 0.19 & 0.75 & 0.75 & 0.93 \\
\hline 19 & 0 & 15.2 & 0.07 & -0.8 & 0.320 & 1.8 & -0.8 & 0.29 & 0.55 & 0.55 & 0.90 \\
\hline 20 & 0 & 15.3 & 0.07 & -0.7 & 0.420 & 1.7 & -0.7 & 0.26 & 0.59 & 0.59 & 0.93 \\
\hline 21 & 0 & 13.1 & 0.10 & -1.1 & 0.320 & 2.1 & -1.1 & 0.13 & 0.63 & 0.63 & 0.93 \\
\hline 22 & 0 & 13.0 & 0.10 & -1.0 & 0.400 & 2.0 & -1.0 & 0.13 & 0.69 & 0.69 & 0.97 \\
\hline 23 & 0 & 12.9 & 0.10 & -0.9 & 0.480 & 1.9 & -0.9 & 0.29 & 0.71 & 0.71 & 1.00 \\
\hline 24 & 0 & 12.8 & 0.10 & -0.8 & 0.560 & 1.8 & -0.8 & 0.23 & 0.75 & 0.75 & 0.93 \\
\hline 25 & 0 & 12.7 & 0.10 & -0.7 & 0.640 & 1.7 & -0.7 & 0.29 & 0.76 & 0.76 & 0.97 \\
\hline 26 & 0 & 10.9 & 0.10 & -1.1 & 0.100 & 2.1 & -1.1 & 0.23 & 0.57 & 0.57 & 0.93 \\
\hline 27 & 0 & 11.0 & 0.10 & -1.0 & 0.200 & 2.0 & -1.0 & 0.32 & 0.57 & 0.57 & 0.90 \\
\hline 28 & 0 & 11.1 & 0.10 & -0.9 & 0.300 & 1.9 & -0.9 & 0.19 & 0.65 & 0.65 & 0.90 \\
\hline 29 & 0 & 11.2 & 0.10 & -0.8 & 0.400 & 1.8 & -0.8 & 0.16 & 0.71 & 0.71 & 0.87 \\
\hline 30 & 0 & 11.3 & 0.10 & -0.7 & 0.500 & 1.7 & -0.7 & 0.29 & 0.78 & 0.78 & 0.90 \\
\hline 31 & 0 & 9.1 & 0.15 & -1.1 & 0.430 & 2.1 & -1.1 & 0.23 & 0.75 & 0.75 & 0.90 \\
\hline 32 & 0 & 9.0 & 0.15 & -1.0 & 0.500 & 2.0 & -1.0 & 0.19 & 0.61 & 0.61 & 0.93 \\
\hline 33 & 0 & 8.9 & 0.15 & -0.9 & 0.570 & 1.9 & -0.9 & 0.35 & 0.65 & 0.65 & 0.90 \\
\hline 34 & 0 & 8.8 & 0.15 & -0.8 & 0.640 & 1.8 & -0.8 & 0.26 & 0.76 & 0.76 & 0.87 \\
\hline 35 & 0 & 8.7 & 0.15 & -0.7 & 0.710 & 1.7 & -0.7 & 0.52 & 0.80 & 0.80 & 0.97 \\
\hline 36 & 0 & 6.9 & 0.15 & -1.1 & 0.100 & 2.1 & -1.1 & 0.26 & 0.47 & 0.47 & 0.90 \\
\hline 37 & 0 & 7.0 & 0.15 & -1.0 & 0.200 & 2.0 & -1.0 & 0.23 & 0.63 & 0.63 & 1.00 \\
\hline
\end{tabular}




\begin{tabular}{|c|c|c|c|c|c|c|c|c|c|c|c|}
\hline 38 & 0 & 7.1 & 0.15 & -0.9 & 0.300 & 1.9 & -0.9 & 0.32 & 0.67 & 0.67 & 0.83 \\
\hline 39 & 0 & 7.2 & 0.15 & -0.8 & 0.400 & 1.8 & -0.8 & 0.19 & 0.63 & 0.63 & 1.00 \\
\hline 40 & 0 & 7.3 & 0.15 & -0.7 & 0.500 & 1.7 & -0.7 & 0.29 & 0.67 & 0.67 & 0.90 \\
\hline 41 & 0 & 7.1 & 0.20 & -1.1 & 0.540 & 2.1 & -1.1 & 0.26 & 0.69 & 0.69 & 0.93 \\
\hline 42 & 0 & 7.0 & 0.20 & -1.0 & 0.600 & 2.0 & -1.0 & 0.42 & 0.73 & 0.73 & 1.00 \\
\hline 43 & 0 & 6.9 & 0.20 & -0.9 & 0.660 & 1.9 & -0.9 & 0.26 & 0.75 & 0.75 & 0.93 \\
\hline 44 & 0 & 6.8 & 0.20 & -0.8 & 0.720 & 1.8 & -0.8 & 0.29 & 0.76 & 0.76 & 0.87 \\
\hline 45 & 0 & 6.7 & 0.20 & -0.7 & 0.780 & 1.7 & -0.7 & 0.42 & 0.76 & 0.76 & 0.87 \\
\hline 46 & 0 & 4.9 & 0.20 & -1.1 & 0.100 & 2.1 & -1.1 & 0.16 & 0.61 & 0.61 & 0.97 \\
\hline 47 & 0 & 5.0 & 0.20 & -1.0 & 0.200 & 2.0 & -1.0 & 0.23 & 0.63 & 0.63 & 0.97 \\
\hline 48 & 0 & 5.1 & 0.20 & -0.9 & 0.300 & 1.9 & -0.9 & 0.26 & 0.69 & 0.69 & 0.93 \\
\hline 49 & 0 & 5.2 & 0.20 & -0.8 & 0.400 & 1.8 & -0.8 & 0.29 & 0.71 & 0.71 & 0.87 \\
\hline 50 & 0 & 5.3 & 0.20 & -0.7 & 0.500 & 1.7 & -0.7 & 0.29 & 0.75 & 0.75 & 0.93 \\
\hline 51 & 0 & 1.1 & 0.80 & -7.1 & -0.540 & -2.1 & 1.1 & 0.10 & 0.49 & 0.49 & 0.80 \\
\hline 52 & 0 & 1.0 & 0.80 & -7.0 & -0.600 & -2.0 & 1.0 & 0.06 & 0.45 & 0.45 & 0.90 \\
\hline 53 & 0 & 0.9 & 0.80 & -6.9 & -0.660 & -1.9 & 0.9 & 0.16 & 0.45 & 0.45 & 0.80 \\
\hline 54 & 0 & 0.8 & 0.80 & -6.8 & -0.720 & -1.8 & 0.8 & 0.48 & 0.39 & 0.39 & 0.83 \\
\hline 55 & 0 & 0.7 & 0.80 & -6.7 & -0.780 & -1.7 & 0.7 & 0.42 & 0.47 & 0.47 & 0.80 \\
\hline 56 & 0 & 1.1 & 0.80 & -4.9 & -0.100 & -2.1 & 1.1 & 0.16 & 0.37 & 0.37 & 0.80 \\
\hline 57 & 0 & 1.0 & 0.80 & -5.0 & -0.200 & -2.0 & 1.0 & 0.10 & 0.39 & 0.39 & 0.83 \\
\hline 58 & 0 & 0.9 & 0.80 & -5.1 & -0.300 & -1.9 & 0.9 & 0.19 & 0.39 & 0.39 & 0.90 \\
\hline 59 & 0 & 0.8 & 0.80 & -5.2 & -0.400 & -1.8 & 0.8 & 0.06 & 0.41 & 0.41 & 0.83 \\
\hline 60 & 0 & 0.7 & 0.80 & -5.3 & -0.500 & -1.7 & 0.7 & 0.19 & 0.51 & 0.51 & 0.90 \\
\hline 61 & 0 & 1.1 & 0.85 & -9.1 & -0.430 & -2.1 & 1.1 & 0.13 & 0.41 & 0.41 & 0.77 \\
\hline 62 & 0 & 1.0 & 0.85 & -9.0 & -0.500 & -2.0 & 1.0 & 0.10 & 0.41 & 0.41 & 0.87 \\
\hline 63 & 0 & 0.9 & 0.85 & -8.9 & -0.570 & -1.9 & 0.9 & 0.19 & 0.45 & 0.45 & 0.87 \\
\hline 64 & 0 & 0.8 & 0.85 & -8.8 & -0.640 & -1.8 & 0.8 & 0.26 & 0.45 & 0.45 & 0.83 \\
\hline 65 & 0 & 0.7 & 0.85 & -8.7 & -0.710 & -1.7 & 0.7 & 0.26 & 0.61 & 0.61 & 0.90 \\
\hline 66 & 0 & 1.1 & 0.85 & -6.9 & -0.100 & -2.1 & 1.1 & 0.13 & 0.41 & 0.41 & 0.90 \\
\hline 67 & 0 & 1.0 & 0.85 & -7.0 & -0.200 & -2.0 & 1.0 & 0.10 & 0.33 & 0.33 & 0.83 \\
\hline 68 & 0 & 0.9 & 0.85 & -7.1 & -0.300 & -1.9 & 0.9 & 0.16 & 0.37 & 0.37 & 0.90 \\
\hline 69 & 0 & 0.8 & 0.85 & -7.2 & -0.400 & -1.8 & 0.8 & 0.13 & 0.49 & 0.49 & 0.87 \\
\hline 70 & 0 & 0.7 & 0.85 & -7.3 & -0.500 & -1.7 & 0.7 & 0.26 & 0.43 & 0.43 & 0.90 \\
\hline 71 & 0 & 1.1 & 0.90 & -13.1 & -0.320 & -2.1 & 1.1 & 0.13 & 0.43 & 0.43 & 0.80 \\
\hline 72 & 0 & 1.0 & 0.90 & -13.0 & -0.400 & -2.0 & 1.0 & 0.19 & 0.39 & 0.39 & 0.77 \\
\hline 73 & 0 & 0.9 & 0.90 & -12.9 & -0.480 & -1.9 & 0.9 & 0.13 & 0.37 & 0.37 & 0.93 \\
\hline 74 & 0 & 0.8 & 0.90 & -12.8 & -0.560 & -1.8 & 0.8 & 0.35 & 0.43 & 0.43 & 0.83 \\
\hline 75 & 0 & 0.7 & 0.90 & -12.7 & -0.640 & -1.7 & 0.7 & 0.32 & 0.49 & 0.49 & 0.90 \\
\hline 76 & 0 & 1.1 & 0.90 & -10.9 & -0.100 & -2.1 & 1.1 & 0.13 & 0.37 & 0.37 & 0.80 \\
\hline 77 & 0 & 1.0 & 0.90 & -11.0 & -0.200 & -2.0 & 1.0 & 0.10 & 0.37 & 0.37 & 0.83 \\
\hline 78 & 0 & 0.9 & 0.90 & -11.1 & -0.300 & -1.9 & 0.9 & 0.10 & 0.41 & 0.41 & 0.87 \\
\hline 79 & 0 & 0.8 & 0.90 & -11.2 & -0.400 & -1.8 & 0.8 & 0.23 & 0.55 & 0.55 & 0.87 \\
\hline
\end{tabular}




$\begin{array}{llllllllllll}80 & 0 & 0.7 & 0.90 & -11.3 & -0.500 & -1.7 & 0.7 & 0.23 & 0.57 & 0.57 & 0.77 \\ 81 & 0 & 1.1 & 0.93 & -17.1 & -0.174 & -2.1 & 1.1 & 0.16 & 0.41 & 0.41 & 0.80 \\ 82 & 0 & 1.0 & 0.93 & -17.0 & -0.260 & -2.0 & 1.0 & 0.19 & 0.29 & 0.29 & 0.80 \\ 83 & 0 & 0.9 & 0.93 & -16.9 & -0.346 & -1.9 & 0.9 & 0.13 & 0.43 & 0.43 & 0.80 \\ 84 & 0 & 0.8 & 0.93 & -16.8 & -0.432 & -1.8 & 0.8 & 0.13 & 0.45 & 0.45 & 0.87 \\ 85 & 0 & 0.7 & 0.93 & -16.7 & -0.518 & -1.7 & 0.7 & 0.32 & 0.49 & 0.49 & 0.87 \\ 86 & 0 & 1.1 & 0.93 & -14.9 & -0.020 & -2.1 & 1.1 & 0.13 & 0.27 & 0.27 & 0.90 \\ 87 & 0 & 1.0 & 0.93 & -15.0 & -0.120 & -2.0 & 1.0 & 0.10 & 0.43 & 0.43 & 0.80 \\ 88 & 0 & 0.9 & 0.93 & -15.1 & -0.220 & -1.9 & 0.9 & 0.06 & 0.43 & 0.43 & 0.87 \\ 89 & 0 & 0.8 & 0.93 & -15.2 & -0.320 & -1.8 & 0.8 & 0.16 & 0.35 & 0.35 & 0.87 \\ 90 & 0 & 0.7 & 0.93 & -15.3 & -0.420 & -1.7 & 0.7 & 0.19 & 0.43 & 0.43 & 0.87 \\ 91 & 0 & 1.1 & 0.95 & -24.1 & -0.160 & -2.1 & 1.1 & 0.13 & 0.47 & 0.47 & 0.80 \\ 92 & 0 & 1.0 & 0.95 & -24.0 & -0.250 & -2.0 & 1.0 & 0.06 & 0.41 & 0.41 & 0.77 \\ 93 & 0 & 0.9 & 0.95 & -23.9 & -0.340 & -1.9 & 0.9 & 0.16 & 0.45 & 0.45 & 0.87 \\ 94 & 0 & 0.8 & 0.95 & -23.8 & -0.430 & -1.8 & 0.8 & 0.19 & 0.49 & 0.49 & 0.77 \\ 95 & 0 & 0.7 & 0.95 & -23.7 & -0.520 & -1.7 & 0.7 & 0.26 & 0.41 & 0.41 & 0.87 \\ 96 & 0 & 1.1 & 0.95 & -21.9 & -0.050 & -2.1 & 1.1 & 0.00 & 0.41 & 0.41 & 0.90 \\ 97 & 0 & 1.0 & 0.95 & -22.0 & -0.150 & -2.0 & 1.0 & 0.10 & 0.39 & 0.39 & 0.90 \\ 98 & 0 & 0.9 & 0.95 & -22.1 & -0.250 & -1.9 & 0.9 & 0.23 & 0.45 & 0.45 & 0.83 \\ 99 & 0 & 0.8 & 0.95 & -22.2 & -0.350 & -1.8 & 0.8 & 0.26 & 0.45 & 0.45 & 0.83 \\ 100 & 0 & 0.7 & 0.95 & -22.3 & -0.450 & -1.7 & 0.7 & 0.23 & 0.43 & 0.43 & 0.90\end{array}$


SM 5. Choices Proportions Consistent with Five Distinct Rules by Subject in Study 4

\begin{tabular}{|c|c|c|c|c|c|}
\hline $\begin{array}{c}\text { X } \\
\text { (rule name) } \\
\text { Participant }\end{array}$ & $\begin{array}{c}\text { Higher } \\
\text { non-median } \\
\text { (EV or } \\
\text { exaggerating) }\end{array}$ & $\begin{array}{c}\text { Higher } \\
\text { median } \\
\text { (Median) }\end{array}$ & $\begin{array}{l}\text { Higher average } \\
\text { of the two } \\
\text { experts } \\
\text { (Average) }\end{array}$ & $\begin{array}{c}\text { Smaller } \\
\text { difference } \\
\text { between the two } \\
\text { experts } \\
\text { (Safe) }\end{array}$ & $\begin{array}{c}\text { Larger } \\
\text { difference } \\
\text { between the two } \\
\text { experts } \\
\text { (Risk) }\end{array}$ \\
\hline \multicolumn{6}{|c|}{ Calibrated1 } \\
\hline 1 & 0.45 & 0.55 & 0.55 & 0.07 & 0.93 \\
\hline 2 & 0.09 & 0.91 & 0.93 & 0.57 & 0.43 \\
\hline 3 & 0.04 & 0.96 & 0.92 & 0.48 & 0.52 \\
\hline 4 & 0.18 & 0.82 & 0.84 & 0.44 & 0.56 \\
\hline 5 & 0.47 & 0.53 & 0.53 & 0.47 & 0.53 \\
\hline 6 & 0.11 & 0.89 & 0.91 & 0.53 & 0.47 \\
\hline 7 & 0.27 & 0.73 & 0.71 & 0.31 & 0.69 \\
\hline 8 & 0.49 & 0.51 & 0.51 & 0.45 & 0.55 \\
\hline 9 & 0.41 & 0.59 & 0.57 & 0.87 & 0.13 \\
\hline 10 & 0.11 & 0.89 & 0.87 & 0.47 & 0.53 \\
\hline 11 & 0.15 & 0.85 & 0.83 & 0.37 & 0.63 \\
\hline 12 & 0.25 & 0.75 & 0.75 & 0.37 & 0.63 \\
\hline 13 & 0.48 & 0.52 & 0.52 & 0.02 & 0.98 \\
\hline 14 & 0.17 & 0.83 & 0.79 & 0.49 & 0.51 \\
\hline 15 & 0.07 & 0.93 & 0.91 & 0.47 & 0.53 \\
\hline 16 & 0.13 & 0.87 & 0.85 & 0.59 & 0.41 \\
\hline 17 & 0.05 & 0.95 & 0.91 & 0.47 & 0.53 \\
\hline 18 & 0.08 & 0.92 & 0.92 & 0.48 & 0.52 \\
\hline 19 & 0.11 & 0.89 & 0.87 & 0.41 & 0.59 \\
\hline 20 & 0.09 & 0.91 & 0.91 & 0.53 & 0.47 \\
\hline 21 & 0.24 & 0.76 & 0.78 & 0.50 & 0.50 \\
\hline 22 & 0.17 & 0.83 & 0.81 & 0.55 & 0.45 \\
\hline 23 & 0.17 & 0.83 & 0.83 & 0.35 & 0.65 \\
\hline 24 & 0.15 & 0.85 & 0.83 & 0.65 & 0.35 \\
\hline 25 & 0.27 & 0.73 & 0.71 & 0.39 & 0.61 \\
\hline 26 & 0.47 & 0.53 & 0.57 & 0.49 & 0.51 \\
\hline 27 & 0.08 & 0.92 & 0.92 & 0.46 & 0.54 \\
\hline 28 & 0.19 & 0.81 & 0.79 & 0.55 & 0.45 \\
\hline 29 & 0.45 & 0.55 & 0.53 & 0.19 & 0.81 \\
\hline 30 & 0.16 & 0.84 & 0.84 & 0.50 & 0.50 \\
\hline 31 & 0.41 & 0.59 & 0.59 & 0.47 & 0.53 \\
\hline \# Best fitted & $\mathbf{0}$ & 21 & 13 & 1 & 5 \\
\hline Min & 0.40 & 0.51 & 0.51 & 0.02 & 0.13 \\
\hline $\operatorname{Max}$ & 0.49 & 0.96 & 0.93 & 0.87 & 0.98 \\
\hline Mean & 0.23 & 0.78 & 0.77 & 0.45 & 0.55 \\
\hline SD & 0.15 & 0.15 & 0.14 & 0.15 & 0.16 \\
\hline $\begin{array}{c}\mathrm{X} \\
\text { (rule name) }\end{array}$ & $\begin{array}{l}\text { Higher } \\
\text { Expected } \\
\text { Value } \\
(\mathrm{EV})\end{array}$ & $\begin{array}{l}\text { Higher } \\
\text { Median } \\
\text { (Median) }\end{array}$ & $\begin{array}{l}\text { Higher average } \\
\text { of the two } \\
\text { experts } \\
\text { (Average) }\end{array}$ & $\begin{array}{c}\text { Smaller } \\
\text { difference } \\
\text { between the two } \\
\text { experts } \\
\text { (Safe) }\end{array}$ & $\begin{array}{c}\text { Larger } \\
\text { difference } \\
\text { between the two } \\
\text { experts } \\
\text { (Risk) }\end{array}$ \\
\hline \multicolumn{6}{|c|}{ Calibrated 100} \\
\hline 1 & 0.39 & 0.61 & 0.63 & 0.37 & 0.63 \\
\hline 2 & 0.65 & 0.35 & 0.37 & 0.33 & 0.67 \\
\hline 3 & 0.52 & 0.48 & 0.50 & 0.50 & 0.50 \\
\hline 4 & 0.49 & 0.51 & 0.51 & 0.01 & 0.99 \\
\hline 5 & 0.36 & 0.64 & 0.64 & 0.4 & 0.6 \\
\hline 6 & 0.46 & 0.54 & 0.54 & 0.2 & 0.8 \\
\hline 7 & 0.47 & 0.53 & 0.53 & 0.05 & 0.95 \\
\hline 8 & 0.63 & 0.37 & 0.41 & 0.31 & 0.69 \\
\hline 9 & 0.55 & 0.45 & 0.47 & 0.55 & 0.45 \\
\hline 10 & 0.09 & 0.91 & 0.87 & 0.45 & 0.55 \\
\hline 11 & 0.49 & 0.51 & 0.53 & 0.49 & 0.51 \\
\hline 12 & 0.39 & 0.61 & 0.65 & 0.21 & 0.79 \\
\hline
\end{tabular}




\begin{tabular}{|c|c|c|c|c|c|}
\hline & & & & & \\
\hline 13 & 0.86 & 0.14 & 0.18 & 0.50 & 0.50 \\
\hline 14 & 0.48 & 0.52 & 0.54 & 0.68 & 0.32 \\
\hline 15 & 0.50 & 0.50 & 0.52 & 0.56 & 0.44 \\
\hline 16 & 0.45 & 0.55 & 0.57 & 0.49 & 0.51 \\
\hline 17 & 0.50 & 0.50 & 0.50 & 0.00 & 1.00 \\
\hline 18 & 0.71 & 0.29 & 0.31 & 0.31 & 0.69 \\
\hline 19 & 0.83 & 0.17 & 0.21 & 0.35 & 0.65 \\
\hline 20 & 0.41 & 0.59 & 0.57 & 0.11 & 0.89 \\
\hline 21 & 0.92 & 0.08 & 0.12 & 0.46 & 0.54 \\
\hline 22 & 0.32 & 0.68 & 0.72 & 0.38 & 0.62 \\
\hline 23 & 0.69 & 0.31 & 0.31 & 0.35 & 0.65 \\
\hline 24 & 0.88 & 0.12 & 0.16 & 0.56 & 0.44 \\
\hline 25 & 0.47 & 0.53 & 0.55 & 0.11 & 0.89 \\
\hline 26 & 0.51 & 0.49 & 0.49 & 0.05 & 0.95 \\
\hline 27 & 0.14 & 0.86 & 0.84 & 0.46 & 0.54 \\
\hline 28 & 0.23 & 0.77 & 0.77 & 0.63 & 0.37 \\
\hline 29 & 0.97 & 0.03 & 0.07 & 0.49 & 0.51 \\
\hline 30 & 0.43 & 0.57 & 0.57 & 0.11 & 0.89 \\
\hline 31 & 0.49 & 0.51 & 0.49 & 0.35 & 0.65 \\
\hline 32 & 0.64 & 0.36 & 0.38 & 0.58 & 0.42 \\
\hline 33 & 0.86 & 0.14 & 0.18 & 0.58 & 0.42 \\
\hline 34 & 0.23 & 0.77 & 0.75 & 0.55 & 0.45 \\
\hline 35 & 0.56 & 0.44 & 0.46 & 0.48 & 0.52 \\
\hline 36 & 0.40 & 0.60 & 0.62 & 0.18 & 0.82 \\
\hline 37 & 0.49 & 0.51 & 0.51 & 0.35 & 0.65 \\
\hline 38 & 0.69 & 0.31 & 0.33 & 0.43 & 0.57 \\
\hline 39 & 0.51 & 0.49 & 0.49 & 0.15 & 0.85 \\
\hline 40 & 0.89 & 0.11 & 0.15 & 0.49 & 0.51 \\
\hline 41 & 0.64 & 0.36 & 0.40 & 0.40 & 0.60 \\
\hline 42 & 0.91 & 0.09 & 0.13 & 0.51 & 0.49 \\
\hline 43 & 0.46 & 0.54 & 0.54 & 0.30 & 0.70 \\
\hline 44 & 0.40 & 0.60 & 0.58 & 0.46 & 0.54 \\
\hline 45 & 0.06 & 0.94 & 0.94 & 0.54 & 0.46 \\
\hline 46 & 0.93 & 0.07 & 0.09 & 0.49 & 0.51 \\
\hline 47 & 0.69 & 0.31 & 0.33 & 0.27 & 0.73 \\
\hline 48 & 0.54 & 0.46 & 0.44 & 0.50 & 0.50 \\
\hline 49 & 0.82 & 0.18 & 0.22 & 0.56 & 0.44 \\
\hline 50 & 0.50 & 0.50 & 0.50 & 0.04 & 0.96 \\
\hline 51 & 0.80 & 0.20 & 0.18 & 0.42 & 0.58 \\
\hline \# Best fitted & 20 & 7 & 7 & 3 & 19 \\
\hline Min & 0.06 & 0.03 & 0.07 & 0 & 0.32 \\
\hline $\operatorname{Max}$ & 0.97 & 0.94 & 0.94 & 0.68 & 1 \\
\hline Mean & 0.55 & 0.45 & 0.46 & 0.37 & 0.63 \\
\hline SD & 0.22 & 0.22 & 0.21 & 0.18 & 0.18 \\
\hline \multicolumn{6}{|c|}{ Biased1 } \\
\hline 1 & 0.49 & 0.51 & 0.49 & 0.19 & 0.81 \\
\hline 2 & 0.32 & 0.68 & 0.32 & 0.30 & 0.70 \\
\hline 3 & 0.06 & 0.94 & 0.06 & 0.50 & 0.50 \\
\hline 4 & 0.50 & 0.50 & 0.50 & 0.02 & 0.98 \\
\hline 5 & 0.57 & 0.43 & 0.57 & 0.55 & 0.45 \\
\hline 6 & 0.50 & 0.50 & 0.50 & 0.12 & 0.88 \\
\hline 7 & 0.56 & 0.44 & 0.56 & 0.62 & 0.38 \\
\hline 8 & 0.30 & 0.70 & 0.30 & 0.44 & 0.56 \\
\hline 9 & 0.19 & 0.81 & 0.19 & 0.51 & 0.49 \\
\hline 10 & 0.54 & 0.46 & 0.54 & 0.34 & 0.66 \\
\hline 11 & 0.08 & 0.92 & 0.08 & 0.50 & 0.50 \\
\hline 12 & 0.56 & 0.44 & 0.56 & 0.48 & 0.52 \\
\hline 13 & 0.47 & 0.53 & 0.47 & 0.23 & 0.77 \\
\hline 14 & 0.45 & 0.55 & 0.45 & 0.29 & 0.71 \\
\hline 15 & 0.18 & 0.82 & 0.18 & 0.52 & 0.48 \\
\hline 16 & 0.22 & 0.78 & 0.22 & 0.54 & 0.46 \\
\hline 17 & 0.38 & 0.62 & 0.38 & 0.40 & 0.60 \\
\hline
\end{tabular}




\begin{tabular}{|c|c|c|c|c|c|}
\hline & & & & & \\
\hline 18 & 0.51 & 0.49 & 0.51 & 0.45 & 0.55 \\
\hline 19 & 0.55 & 0.45 & 0.55 & 0.49 & 0.51 \\
\hline 20 & 0.45 & 0.55 & 0.45 & 0.37 & 0.63 \\
\hline 21 & 0.10 & 0.90 & 0.10 & 0.44 & 0.56 \\
\hline 22 & 0.06 & 0.94 & 0.06 & 0.52 & 0.48 \\
\hline 23 & 0.53 & 0.47 & 0.53 & 0.91 & 0.09 \\
\hline 24 & 0.37 & 0.63 & 0.37 & 0.69 & 0.31 \\
\hline 25 & 0.43 & 0.57 & 0.43 & 0.43 & 0.57 \\
\hline 26 & 0.61 & 0.39 & 0.61 & 0.31 & 0.69 \\
\hline 27 & 0.46 & 0.54 & 0.46 & 0.16 & 0.84 \\
\hline 28 & 0.46 & 0.54 & 0.46 & 0.68 & 0.32 \\
\hline 29 & 0.20 & 0.80 & 0.20 & 0.40 & 0.60 \\
\hline 30 & 0.18 & 0.82 & 0.18 & 0.64 & 0.36 \\
\hline 31 & 0.59 & 0.41 & 0.59 & 0.61 & 0.39 \\
\hline 32 & 0.56 & 0.44 & 0.56 & 0.50 & 0.50 \\
\hline 33 & 0.47 & 0.53 & 0.47 & 0.41 & 0.59 \\
\hline 34 & 0.44 & 0.56 & 0.44 & 0.14 & 0.86 \\
\hline 35 & 0.24 & 0.76 & 0.24 & 0.58 & 0.42 \\
\hline 36 & 0.48 & 0.52 & 0.48 & 0.26 & 0.74 \\
\hline 37 & 0.48 & 0.52 & 0.48 & 0.78 & 0.22 \\
\hline 38 & 0.24 & 0.76 & 0.24 & 0.36 & 0.64 \\
\hline 39 & 0.76 & 0.24 & 0.76 & 0.52 & 0.48 \\
\hline 40 & 0.49 & 0.51 & 0.49 & 0.53 & 0.47 \\
\hline 41 & 0.58 & 0.42 & 0.58 & 0.46 & 0.54 \\
\hline 42 & 0.04 & 0.96 & 0.04 & 0.48 & 0.52 \\
\hline 43 & 0.39 & 0.61 & 0.39 & 0.45 & 0.55 \\
\hline 44 & 0.38 & 0.62 & 0.38 & 0.66 & 0.34 \\
\hline 45 & 0.14 & 0.86 & 0.14 & 0.54 & 0.46 \\
\hline 46 & 0.56 & 0.44 & 0.56 & 0.32 & 0.68 \\
\hline 47 & 0.67 & 0.33 & 0.67 & 0.37 & 0.63 \\
\hline 48 & 0.67 & 0.33 & 0.67 & 0.25 & 0.75 \\
\hline 49 & 0.47 & 0.53 & 0.47 & 0.97 & 0.03 \\
\hline 50 & 0.14 & 0.86 & 0.14 & 0.36 & 0.64 \\
\hline 51 & 0.14 & 0.86 & 0.14 & 0.56 & 0.44 \\
\hline 52 & 0.25 & 0.75 & 0.25 & 0.35 & 0.65 \\
\hline 53 & 0.18 & 0.82 & 0.18 & 0.44 & 0.56 \\
\hline 54 & 0.23 & 0.77 & 0.23 & 0.51 & 0.49 \\
\hline 55 & 0.48 & 0.52 & 0.48 & 0.40 & 0.60 \\
\hline 56 & 0.37 & 0.63 & 0.37 & 0.43 & 0.57 \\
\hline 57 & 0.06 & 0.94 & 0.06 & 0.44 & 0.56 \\
\hline 58 & 0.15 & 0.85 & 0.15 & 0.43 & 0.57 \\
\hline 59 & 0.10 & 0.90 & 0.10 & 0.52 & 0.48 \\
\hline \# Best fitted & 7 & 26 & 7 & 9 & 18 \\
\hline Min & 0.04 & 0.24 & 0.04 & 0.02 & 0.03 \\
\hline $\operatorname{Max}$ & 0.76 & 0.96 & 0.76 & 0.97 & 0.98 \\
\hline Mean & 0.37 & 0.63 & 0.37 & 0.45 & 0.55 \\
\hline SD & 0.19 & 0.19 & 0.19 & 0.17 & 0.17 \\
\hline \multicolumn{6}{|c|}{ Biased100 } \\
\hline 1 & 0.96 & 0.04 & 0.96 & 0.50 & 0.50 \\
\hline 2 & 0.97 & 0.03 & 0.97 & 0.53 & 0.47 \\
\hline 3 & 0.52 & 0.48 & 0.52 & 0.02 & 0.98 \\
\hline 4 & 0.97 & 0.03 & 0.97 & 0.49 & 0.51 \\
\hline 5 & 0.96 & 0.04 & 0.96 & 0.50 & 0.50 \\
\hline 6 & 0.96 & 0.04 & 0.96 & 0.52 & 0.48 \\
\hline 7 & 0.99 & 0.01 & 0.99 & 0.49 & 0.51 \\
\hline 8 & 1.00 & 0.00 & 1.00 & 0.50 & 0.50 \\
\hline 9 & 0.89 & 0.11 & 0.89 & 0.41 & 0.59 \\
\hline 10 & 0.77 & 0.23 & 0.77 & 0.47 & 0.53 \\
\hline 11 & 0.81 & 0.19 & 0.81 & 0.55 & 0.45 \\
\hline 12 & 0.42 & 0.58 & 0.42 & 0.38 & 0.62 \\
\hline 13 & 0.85 & 0.15 & 0.85 & 0.39 & 0.61 \\
\hline 14 & 0.95 & 0.05 & 0.95 & 0.49 & 0.51 \\
\hline
\end{tabular}




\begin{tabular}{|c|c|c|c|c|c|}
\hline 15 & 0.92 & 0.08 & 0.92 & 0.52 & 0.48 \\
\hline 16 & 0.94 & 0.06 & 0.94 & 0.44 & 0.56 \\
\hline 17 & 0.99 & 0.01 & 0.99 & 0.51 & 0.49 \\
\hline 18 & 0.76 & 0.24 & 0.76 & 0.60 & 0.40 \\
\hline 19 & 0.56 & 0.44 & 0.56 & 0.08 & 0.92 \\
\hline 20 & 0.95 & 0.05 & 0.95 & 0.53 & 0.47 \\
\hline 21 & 0.87 & 0.13 & 0.87 & 0.49 & 0.51 \\
\hline 22 & 1.00 & 0.00 & 1.00 & 0.50 & 0.50 \\
\hline 23 & 1.00 & 0.00 & 1.00 & 0.50 & 0.50 \\
\hline 24 & 0.95 & 0.05 & 0.95 & 0.47 & 0.53 \\
\hline 25 & 0.98 & 0.02 & 0.98 & 0.52 & 0.48 \\
\hline 26 & 0.92 & 0.08 & 0.92 & 0.50 & 0.50 \\
\hline 27 & 0.93 & 0.07 & 0.93 & 0.45 & 0.55 \\
\hline 28 & 0.98 & 0.02 & 0.98 & 0.50 & 0.50 \\
\hline 29 & 0.98 & 0.02 & 0.98 & 0.50 & 0.50 \\
\hline 30 & 0.87 & 0.13 & 0.87 & 0.39 & 0.61 \\
\hline \# Best fitted & 27 & $\mathbf{0}$ & 27 & 0 & 3 \\
\hline Min & 0.42 & 0 & 0.42 & 0.02 & 0.4 \\
\hline Max & 1 & 0.58 & 1 & 0.6 & 0.98 \\
\hline Mean & 0.89 & 0.11 & 0.89 & 0.46 & 0.54 \\
\hline SD & 0.15 & 0.15 & 0.15 & 0.12 & 0.12 \\
\hline
\end{tabular}

Notes. Table 3's notations and format. 